\title{
Effects of the Predominant Pulse on the Inelastic Displacement Ratios of Pulse-Like Ground Motions Based on Wavelet Analysis
}

\author{
Guochen Zhao $\mathbb{D},,^{1,2}$ Jingzhou Zhu $\mathbb{D},^{2}$ Xingji Zhu $\mathbb{D}^{2},{ }^{2}$ and Longjun $\mathrm{Xu} \mathbb{D}^{1}$ \\ ${ }^{1}$ State Key Laboratory of Fine Blasting Jointly Established by the Ministry and the Province, Jianghan University, \\ Wuhan 430056, China \\ ${ }^{2}$ School of Ocean Engineering, Harbin Institute of Technology at Weihai, Weihai 264209, China \\ Correspondence should be addressed to Longjun Xu; xulongjun80@163.com
}

Received 7 April 2021; Revised 29 October 2021; Accepted 3 December 2021; Published 21 December 2021

Academic Editor: Antonello Troncone

Copyright (C) 2021 Guochen Zhao et al. This is an open access article distributed under the Creative Commons Attribution License, which permits unrestricted use, distribution, and reproduction in any medium, provided the original work is properly cited.

\begin{abstract}
Having a predominant pulse is the main feature for pulse-like ground motions differing from others. To investigate the influence of the predominant pulse on the inelastic displacement ratios of pulse-like ground motions, the wavelet analysis method is used to extract the predominant pulse. The results indicate that the inelastic displacement ratios of the pulse-removed parts obtained by subtracting the extracted pulse from the original pulse-like ground motions are close to the results of non-pulse-like ground motions. The ratio of the energy of the extracted pulse to the energy of the original ground motion is used to represent the pulse intensity. The results indicate that the pulse period determines the locations in which the inelastic displacement ratios would have noticeable increments, and the pulse intensity determines the degree of the increments. Besides, the effects of five commonly used parameters (PGV, PGD, PGV/PGA, Arias intensity $I_{\mathrm{a}}$, and soil condition) on the inelastic displacement ratios of pulse-like ground motions and their relations to the pulse period and the pulse intensity are studied. Finally, a new model, in which the influence of pulse intensity is considered, to predict the inelastic displacement ratios of pulse-like ground motions is proposed.
\end{abstract}

\section{Introduction}

Recently, displacement rather than force is starting to become an essential demand parameter for the design, evaluation, and rehabilitation of structures $[1,2]$. One of the challenges in the displacement-based seismic design procedure is to estimate the inelastic displacement demands of structures during earthquake ground shaking. Inelastic displacement ratio, which is defined as the ratio of the maximum inelastic displacement of a single-degree-offreedom (SDOF) system to the maximum elastic displacement of the same system, provides a simple procedure for estimating the maximum lateral inelastic displacement demand of a structure from its corresponding maximum elastic displacement demand [3-5]. Pulse-like ground motion is characterized by one or more large-amplitude and long-period pulses. This type of motion is generally particular to the forward direction, where the fault rupture propagates towards the site at a velocity close to the shear wave velocity [6]. Many studies have revealed that this type of motion can cause severe damage to structures [7-14]. Some studies have shown that the mean inelastic displacement ratios of pulse-like ground motions are different from those of ordinary ground motions $[15,16]$. A better understanding of the inelastic displacement ratios of pulselike ground motions can enhance the seismic design of structures in the near-fault zone.

Having a clear predominant pulse is the main feature for pulse-like ground motions differing from others. When the predominant pulse is removed, the inelastic displacement ratios of pulse-like ground motions will decrease apparently at medium periods [17]. The pulse period and the pulse intensity are the two key parameters to describe the pulse features. Many studies have analyzed the effects of the pulse period [18-20], ground motion parameters $[15,17,21]$, and structural characteristics, such as nonlinear behavior $[20,22,23]$ and soil-structure interaction [24]. However, to the best of our knowledge, there is no study on the impact of pulse intensity. A reason is that it is usually challenging to define the pulse intensity because the amplitude parameters 
(e.g., PGA, PGV, and PGD) can only represent the original ground motion rather than the pulse that is included in the original ground motion. Previous studies have revealed that the inelastic displacement ratios of pulse-like ground motions would have noticeable increments in the period region related to the pulse period $[25,26]$. However, further studies are needed to investigate the key factors that can affect the degree of the increments and to include this effect into the prediction equations for the inelastic displacement ratios of pulse-like ground motions. Investigating the effects of some ground motion parameters on the inelastic displacement ratios of pulse-like ground motions is very meaningful in some relevant areas, such as the ground motion selection for the seismic design of structures in the near-fault zone. Some studies have pointed out that the peak ground velocity (PGV) [15], maximum incremental velocity (MIV) [15], and PGV/PGA could significantly affect the inelastic displacement ratios of pulse-like ground motions [26]. In view of that, the predominant pulse is the main reason causing the difference of the inelastic displacement ratios for pulse-like ground motions differing from others; further studies are needed to analyze the relations of the commonly used parameters to the pulse period and the pulse intensity.

To further analyze the effects of the predominant pulse on the inelastic displacement ratios, this paper adopts the wavelet analysis method to extract the predominant pulse of pulse-like ground motions and then obtain the pulse-removed part by subtracting the extracted pulse from the original ground motion. The inelastic displacement ratios of the pulse-removed part and those of the ordinary ground motions are compared. The influence of the pulse period and the pulse intensity are discussed. The effects of five commonly used parameters (PGV, PGD, PGV/PGA, Arias intensity, and soil condition) and their relations to the pulse period and the pulse intensity are also analyzed. To facilitate the use in practice, a new prediction equation is proposed to estimate the mean inelastic displacement ratios of pulse-like ground motions. The pulse intensity is included in the equation as a parameter to control the degree of the increments of the inelastic displacement ratios at medium periods.

\section{Pulse-Like Ground Motions Utilized in This Paper}

Subjective errors usually exist in selecting pulse-like ground motions because the selection process is generally based on visual inspection by checking whether visible velocity pulses are contained in the target ground motions. Some quantitative methods have been proposed to identify pulse-like ground motions to eliminate subjective errors [27-32]. The forward-directivity effect and the fling-step effect are the two main reasons for generating pulse-like ground motions. However, all the quantitative methods do not consider the physical mechanisms. Some studies have shown that it does not affect the validity of the analysis results about pulse-like ground motions because pulses will cause similar effects regardless of their causal mechanism [27].
By using the abovementioned quantitative identification methods [27-32], some ground motions with visual ambiguous velocity pulse can be automatically classified as pulse-like or non-pulse-like. As a result, the subjective errors caused by traditional visual identification can be avoided. This paper aims to study the inelastic ratios of typical pulselike ground motions rather than to classify ambiguous ground motions as pulse-like or non-pulse-like. The visually ambiguous pulse-like ground motions might confuse the analysis results. To avoid this problem, a set of more representative pulse-like ground motions are selected in this paper. If a ground motion is classified as pulse-like ground motions by more than one quantitative identification method, the ground motion is assumed to have clear pulse features. Two quantitative methods, the method of Baker [27] and the method of Zhao et al. [31], are adopted in this paper. In Baker's method [27], 91 pulse-like ground motions are selected from the NGA-West 1 ground motion database. By applying the identification method of Zhao et al. [31], 70 of them are also classified as pulse-like.

Pulse-like ground motions are usually concentrated in the near-fault region during large earthquakes. To be more representative, the "closest distance" from the site to the fault rupture plane of the ground motions selected in this paper is no more than $20 \mathrm{~km}$, and the moment magnitude $M_{\mathrm{w}} \geq 5$. High-velocity amplitude is one of the main features of pulselike ground motions. A PGV threshold level of above $30 \mathrm{~cm} /$ $\mathrm{s}$ was usually chosen as one criterion in the selection of pulse-like ground motion [27, 28, 31]. This paper adopts the same criterion. Finally, a total of 58 pulse-like ground motions are selected among the 70 recordings. Bray and Rodriguez-Marek [33] collected a set of 54 pulse-like ground motions caused by the forward directivity. Seven ground motions, which are not included in the 70 recordings but have visually clear velocity pulse and are classified as pulselike by the method of Zhao et al. [31], are selected from the 54 recordings to enlarge the dataset. Figure 1 shows the scatter plot of the dataset in magnitude-distance space. Table 1 presents the detailed information of the 65 pulse-like ground motions. The asterisk before the station name denotes that the ground motion is selected from the dataset of Bray and Rodriguez-Marek [33].

\section{Inelastic Displacement Ratios}

Figure 2 shows the force-deformation relationship of an elastoplastic system. The elastic stiffness is $k$, and the postyield stiffness is 0 . The yield strength is $f_{\mathrm{y}}$, and the yield displacement is $u_{\mathrm{y}} . f_{0}$ is the minimum yield strength required for the system to remain elastic during the excitation of a ground motion, and $u_{0}$ is the corresponding displacement. $U_{\mathrm{m}}$ is the maximum displacement of the elastoplastic system. Inelastic displacement ratio $C$ is expressed mathematically as follows:

$$
C=\frac{u_{m}}{u_{0}}
$$

This paper analyzes the constant-ductility inelastic displacement ratio $C_{\mu}$. $\mu$ is the ratio of $u_{\mathrm{m}}$ to $u_{\mathrm{y}}$ and is 


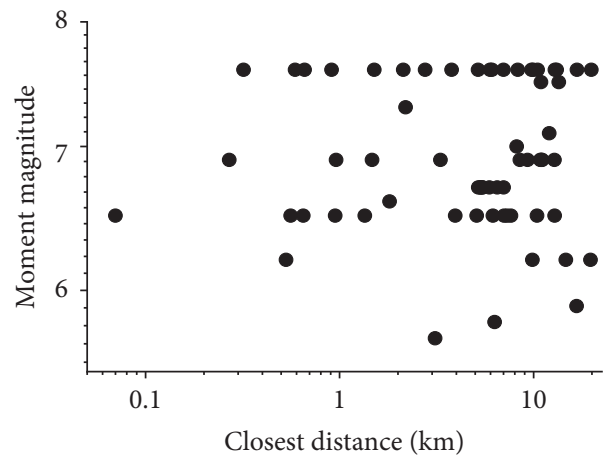

FIGURE 1: Scatter plot of the pulse-like ground motions utilized in this paper in magnitude-distance space.

TABLE 1: Information of the pulse-like ground motions utilized in this paper.

\begin{tabular}{|c|c|c|c|c|c|c|c|c|c|c|}
\hline No. & Earthquake & Station & $\begin{array}{c}R \\
(\mathrm{~km})\end{array}$ & $\begin{array}{l}V_{\mathrm{s}, 30} \\
(\mathrm{~m} / \mathrm{s})\end{array}$ & $T_{\mathrm{p}}(\mathrm{s})$ & $\begin{array}{c}\text { PGA } \\
(\mathrm{g})\end{array}$ & $\begin{array}{c}\text { PGV } \\
(\mathrm{cm} / \mathrm{s})\end{array}$ & $\begin{array}{l}\text { PGD } \\
(\mathrm{cm})\end{array}$ & $\begin{array}{c}I_{\mathrm{a}} \\
(\mathrm{m} / \mathrm{s})\end{array}$ & PI \\
\hline 1 & $\begin{array}{l}\text { San Fernando } \\
\left(1971, M_{\mathrm{w}}=6.6\right)\end{array}$ & $\begin{array}{c}\text { Pacoima Dam (upper left } \\
\text { abutment) }\end{array}$ & 1.81 & 2016.1 & 1.64 & 1.38 & 124.08 & 36.21 & 11.41 & 0.48 \\
\hline 2 & $\begin{array}{c}\text { Coyote Lake } \\
\left(1979, M_{\mathrm{w}}=5.7\right)\end{array}$ & Gilroy Array \#6 & 3.11 & 663.3 & 1.23 & 0.45 & 50.54 & 12.66 & 0.87 & 0.68 \\
\hline 3 & & Agrarias & 0.65 & 274.5 & 2.39 & 0.30 & 54.25 & 14.38 & 1.10 & 0.60 \\
\hline 4 & & Brawley Airport & 10.42 & 208.7 & 4.40 & 0.16 & 37.39 & 26.24 & 0.32 & 0.48 \\
\hline 5 & & EC County Center FF & 7.31 & 192.1 & 4.43 & 0.22 & 72.15 & 50.42 & 0.68 & 0.61 \\
\hline 6 & & EC Meloland Overpass FF & 0.07 & 186.2 & 3.42 & 0.38 & 118.61 & 48.49 & 1.44 & 0.76 \\
\hline 7 & & El Centro Array \#10 & 6.17 & 202.9 & 4.52 & 0.20 & 56.23 & 39.88 & 0.56 & 0.55 \\
\hline 8 & Imperial Valley (1979, & El Centro Array \#3 & 12.85 & 162.9 & 4.50 & 0.28 & 56.89 & 29.43 & 0.83 & 0.60 \\
\hline 9 & $\left.M_{\mathrm{w}}=6.5\right)$ & El Centro Array \#4 & 7.05 & 208.9 & 4.79 & 0.37 & 82.32 & 76.29 & 0.99 & 0.75 \\
\hline 10 & & El Centro Array \#5 & 3.95 & 205.6 & 4.13 & 0.38 & 98.31 & 77.75 & 1.75 & 0.74 \\
\hline 11 & & El Centro Array \#6 & 1.35 & 203.2 & 3.77 & 0.44 & 124.02 & 76.28 & 1.98 & 0.85 \\
\hline 12 & & El Centro Array \#7 & 0.56 & 210.5 & 4.38 & 0.47 & 114.09 & 50.04 & 1.70 & 0.75 \\
\hline 13 & & El Centro Differential Array & 5.09 & 202.3 & 6.27 & 0.35 & 74.87 & 56.19 & 1.78 & 0.52 \\
\hline 14 & & Holtville Post Office & 7.65 & 202.9 & 4.82 & 0.24 & 74.78 & 42.57 & 0.91 & 0.72 \\
\hline 15 & $\begin{array}{c}\text { Irpinia, Italy } \\
\left(1980, M_{\mathrm{w}}=6.9\right)\end{array}$ & Sturno & 10.84 & 1000.0 & 3.27 & 0.32 & 72.52 & 30.11 & 1.39 & 0.68 \\
\hline 16 & $\begin{array}{l}\text { Westmorland } \\
\left(1981, M_{\mathrm{w}}=5.9\right)\end{array}$ & Parachute Test Site & 16.66 & 348.7 & 4.36 & 0.19 & 61.91 & 37.23 & 0.71 & 0.47 \\
\hline 17 & Morgan Hill & Coyote Lake Dam (SW abutment) & 0.53 & 597.1 & 1.07 & 1.31 & 78.29 & 16.05 & 3.85 & 0.76 \\
\hline 18 & $\left(1984, M_{\mathrm{w}}=6.2\right)$ & Gilroy Array \#6 & 9.86 & 663.3 & 1.22 & 0.27 & 38.00 & 6.38 & 0.92 & 0.67 \\
\hline 19 & $\begin{array}{c}\text { San Salvador } \\
\left(1986, M_{\mathrm{w}}=5.8\right)\end{array}$ & Geotech Investigation Center & 6.30 & 545.0 & 0.81 & 0.69 & 69.47 & 13.52 & 3.12 & 0.50 \\
\hline 20 & $\begin{array}{l}\text { Superstition Hills } \\
\left(1987, M_{\mathrm{w}}=6.5\right)\end{array}$ & Parachute Test Site & 0.95 & 348.7 & 2.39 & 0.45 & 146.89 & 53.85 & 3.90 & 0.59 \\
\hline 21 & & ${ }^{*}$ Gilroy_historic bldg. & 10.97 & 338.5 & 1.65 & 0.28 & 44.43 & 10.55 & 0.73 & 0.62 \\
\hline 22 & & Gilroy Array \#2 & 11.07 & 270.8 & 1.72 & 0.40 & 47.13 & 20.62 & 1.50 & 0.60 \\
\hline 23 & Loma Prieta & * Gilroy Array \#3 & 12.82 & 349.9 & 2.64 & 0.36 & 45.64 & 25.06 & 1.38 & 0.52 \\
\hline 24 & $\left(1989, M_{\mathrm{w}}=6.9\right)$ & Saratoga-Aloha Ave & 8.50 & 370.8 & 4.57 & 0.31 & 54.50 & 37.30 & 1.22 & 0.51 \\
\hline 25 & & ${ }^{*}$ Saratoga-West Valley College & 9.31 & 370.8 & 5.65 & 0.28 & 63.17 & 39.53 & 1.16 & 0.61 \\
\hline 26 & $\begin{array}{l}\text { Cape Mendocino } \\
\left(1992, M_{\mathrm{w}}=7\right)\end{array}$ & Petrolia & 8.18 & 712.8 & 3.00 & 0.71 & 98.36 & 36.75 & 4.10 & 0.45 \\
\hline 27 & $\begin{array}{c}\text { Landers }\left(1992, M_{\mathrm{w}}=\right. \\
7.3)\end{array}$ & Lucerne & 2.19 & 684.9 & 5.12 & 0.72 & 134.82 & 118.16 & 7.03 & 0.68 \\
\hline
\end{tabular}


TABle 1: Continued.

\begin{tabular}{|c|c|c|c|c|c|c|c|c|c|c|}
\hline No. & Earthquake & Station & $\begin{array}{c}R \\
(\mathrm{~km})\end{array}$ & $\begin{array}{l}V_{\mathrm{s}, 30} \\
(\mathrm{~m} / \mathrm{s})\end{array}$ & $T_{\mathrm{p}}(\mathrm{s})$ & $\begin{array}{c}\text { PGA } \\
(\mathrm{g})\end{array}$ & $\begin{array}{l}\text { PGV } \\
(\mathrm{cm} / \mathrm{s})\end{array}$ & $\begin{array}{l}\text { PGD } \\
(\mathrm{cm})\end{array}$ & $\begin{array}{c}I_{\mathrm{a}} \\
(\mathrm{m} / \mathrm{s})\end{array}$ & PI \\
\hline 28 & \multirow{10}{*}{$\begin{array}{l}\text { Northridge (1994, } \\
\left.\qquad M_{\mathrm{w}}=6.7\right)\end{array}$} & Jensen Filter Plant & 5.43 & 373.1 & 3.14 & 0.38 & 103.48 & 45.80 & 2.68 & 0.64 \\
\hline 29 & & Jensen Filter Plant Generator & 5.43 & 525.8 & 3.53 & 0.51 & 67.33 & 41.98 & 2.60 & 0.73 \\
\hline 30 & & LA Dam & 5.92 & 629.0 & 1.62 & 0.47 & 87.86 & 26.73 & 1.90 & 0.50 \\
\hline 31 & & Newhall-W Pico Canyon Rd. & 5.48 & 285.9 & 3.01 & 0.41 & 120.49 & 42.20 & 1.57 & 0.66 \\
\hline 32 & & Pacoima Dam (upper left) & 7.01 & 2016.1 & 0.84 & 1.42 & 107.30 & 21.20 & 10.94 & 0.41 \\
\hline 33 & & Rinaldi Receiving Sta & 6.50 & 282.3 & 1.25 & 0.88 & 151.68 & 44.12 & 8.43 & 0.61 \\
\hline 34 & & Sylmar-Converter Sta & 5.35 & 251.2 & 2.98 & 0.64 & 108.25 & 36.62 & 5.77 & 0.43 \\
\hline 35 & & Sylmar-Converter Sta East & 5.19 & 370.5 & 3.61 & 0.84 & 116.19 & 34.81 & 4.31 & 0.57 \\
\hline 36 & & Sylmar-Olive View Med FF & 5.30 & 440.5 & 2.32 & 0.80 & 133.09 & 36.42 & 4.44 & 0.51 \\
\hline 37 & & * KJMA & 0.96 & 312.0 & 1.09 & 0.86 & 107.14 & 27.08 & 9.48 & 0.39 \\
\hline 38 & \multirow{3}{*}{$\begin{array}{c}\text { Kobe, Japan } \\
\left(1995, M_{\mathrm{w}}=6.9\right)\end{array}$} & Port Island $(0 \mathrm{~m})$ & 3.31 & 198.0 & 2.83 & 0.43 & 104.96 & 49.79 & 2.47 & 0.55 \\
\hline 39 & & Takarazuka & 0.27 & 312.0 & 1.82 & 0.66 & 97.26 & 29.87 & 3.84 & 0.48 \\
\hline 40 & & Takatori & 1.47 & 256.0 & 1.55 & 0.75 & 156.14 & 45.27 & 10.72 & 0.46 \\
\hline 41 & \multirow{11}{*}{$\begin{array}{c}\text { Kocaeli, Turkey } \\
\left(1999, M_{\mathrm{w}}=7.5\right)\end{array}$} & ${ }^{*}$ Arcelik & 13.49 & 523.0 & 7.79 & 0.13 & 41.00 & 36.54 & 0.21 & 0.81 \\
\hline 42 & & Gebze & 10.92 & 792.0 & 5.99 & 0.17 & 54.07 & 45.45 & 0.39 & 0.74 \\
\hline 43 & & CHY006 & 9.77 & 438.2 & 2.57 & 0.32 & 59.44 & 22.82 & 2.06 & 0.41 \\
\hline 44 & & CHY101 & 9.96 & 258.9 & 5.34 & 0.39 & 110.93 & 73.93 & 3.03 & 0.74 \\
\hline 45 & & TCU036 & 19.84 & 272.6 & 5.38 & 0.13 & 64.42 & 56.74 & 0.89 & 0.70 \\
\hline 46 & & TCU046 & 16.74 & 465.6 & 8.04 & 0.14 & 31.92 & 43.81 & 0.49 & 0.79 \\
\hline 47 & & TCU049 & 3.78 & 487.3 & 10.22 & 0.30 & 57.51 & 75.38 & 1.32 & 0.64 \\
\hline 48 & & ${ }^{*}$ TCU052 & 0.66 & 579.1 & 11.96 & 0.51 & 213.11 & 308.24 & 4.71 & 0.61 \\
\hline 49 & & TCU053 & 5.97 & 454.6 & 13.12 & 0.22 & 37.83 & 66.71 & 0.93 & 0.58 \\
\hline 50 & & TCU056 & 10.50 & 272.6 & 8.94 & 0.17 & 46.19 & 52.33 & 0.87 & 0.47 \\
\hline 51 & & TCU065 & 0.59 & 305.9 & 5.74 & 0.81 & 139.16 & 112.28 & 8.42 & 0.49 \\
\hline 52 & \multirow{11}{*}{$\begin{array}{l}\text { Chi-Chi, Taiwan } \\
\left(1999, M_{\mathrm{w}}=7.6\right)\end{array}$} & TCU068 & 0.32 & 487.3 & 12.29 & 0.47 & 348.65 & 501.94 & 4.05 & 0.69 \\
\hline 53 & & TCU075 & 0.91 & 573.0 & 4.98 & 0.31 & 106.91 & 100.70 & 2.90 & 0.55 \\
\hline 54 & & TCU076 & 2.76 & 615.0 & 4.73 & 0.42 & 72.61 & 52.66 & 3.94 & 0.41 \\
\hline 55 & & TCU082 & 5.18 & 472.8 & 8.08 & 0.21 & 57.27 & 96.34 & 1.17 & 0.54 \\
\hline 56 & & TCU087 & 7.00 & 473.9 & 10.40 & 0.12 & 46.43 & 60.57 & 0.45 & 0.74 \\
\hline 57 & & TCU101 & 2.13 & 272.6 & 10.33 & 0.18 & 78.16 & 80.34 & 0.79 & 0.68 \\
\hline 58 & & TCU102 & 1.51 & 714.3 & 9.57 & 0.30 & 106.75 & 106.28 & 2.11 & 0.45 \\
\hline 59 & & TCU103 & 6.10 & 494.1 & 8.69 & 0.13 & 68.45 & 69.19 & 0.68 & 0.71 \\
\hline 60 & & TCU104 & 12.89 & 473.9 & 7.19 & 0.10 & 57.19 & 59.50 & 0.45 & 0.52 \\
\hline 61 & & TCU128 & 13.15 & 599.6 & 9.02 & 0.13 & 61.89 & 81.48 & 0.63 & 0.76 \\
\hline 62 & & TCU136 & 8.29 & 473.9 & 8.88 & 0.14 & 62.71 & 65.80 & 0.47 & 0.72 \\
\hline 63 & $\begin{array}{c}\text { Duzce, Turkey } \\
\left(1999, M_{\mathrm{w}}=7.1\right)\end{array}$ & ${ }^{*}$ Bolu & 12.04 & 326.0 & 0.88 & 0.82 & 66.80 & 12.95 & 2.54 & 0.46 \\
\hline 64 & Chi-Chi, Taiwan & СHY024 & 19.65 & 427.7 & 3.19 & 0.19 & 33.30 & 19.59 & 0.41 & 0.59 \\
\hline 65 & $\left(1999, M_{\mathrm{w}}=6.2\right)$ & TCU076 & 14.66 & 615.0 & 0.92 & 0.53 & 62.62 & 10.72 & 1.05 & 0.58 \\
\hline
\end{tabular}

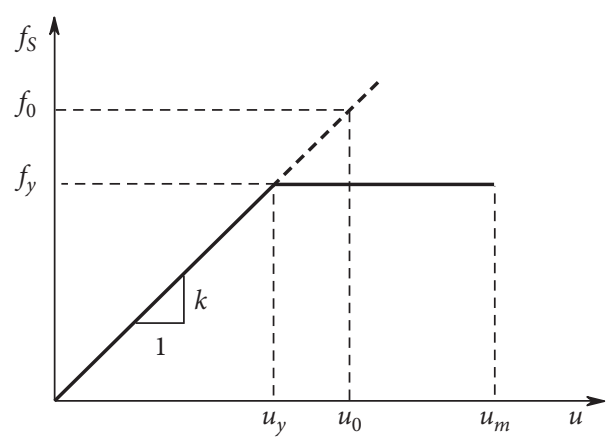

FIGURE 2: Force-deformation relationship of an elastoplastic single-degree-of-freedom system and the corresponding elastic system.

usually termed as ductility factor. To compute the inelastic displacement ratio $C_{\mu}$ for a specified ductility factor, an iterative procedure is needed because the yield strength corresponding to a selected $\mu$ cannot be determined directly [16]. For each ground motion, this paper computes the inelastic displacement ratio $C_{\mu}(\mu=2,3,4,5$, and 6) at 
45 vibration periods between $0.03 \mathrm{~s}$ and $5 \mathrm{~s}$. The damping ratio $\xi$ of the elastoplastic system is defined as $5 \%$.

\section{Extract the Predominant Pulse of Pulse-Like Ground Motions}

Wavelet analysis has high-efficiency and high-performance in the representation of nonstationary signals and has undergone rapid application development in earthquake ground motions, especially for pulse-like ground motions $[27,29]$. In Fourier analysis, a signal is represented by a linear combination of a set of infinite-length and singlefrequency sine waves. In contrast, wavelet analysis represents a signal as a summation of wavelets. This paper adopts the wavelet analysis to extract the predominant pulse. There is a wide literature available regarding theoretical features of the approach as well as algorithmic details, so only a brief overview of the most relevant features is provided here.

Any signal $f(t)$ can be represented as a linear combination of the wavelet basis functions, and the coefficients can be determined by the following equation:

$$
C_{s, l}=\int_{-\infty}^{\infty} f(t) \Phi_{s, l}(t) \mathrm{d} t=\frac{1}{\sqrt{s}} \int_{-\infty}^{\infty} f(t) \Phi\left(\frac{t-l}{s}\right) \mathrm{d} t,
$$

where $\Phi(t)$ is a mother wavelet function and $s$ and $l$ are the parameters used to scale and translate the mother wavelet function.

Daubechies wavelet of order $4(\mathrm{db} 4)$ is usually used as the mother wavelet to analyze ground motions and is utilized in this paper. The largest absolute coefficient is usually sufficient to identify the period and location of the predominant velocity pulse. To represent the predominant pulse in a detailed manner, Baker [27] recommended using a total of ten coefficients in the identified scale and location window. Figure 3 shows the time histories of the original ground motion and its final extracted predominant pulse. To quantitatively analyze the contribution of the predominant pulse on the inelastic displacement ratios, the extracted pulse is subtracted from the original ground motion. This part is termed as "pulse-removed" part in this paper. The right panel of Figure 3 shows the time histories of the pulse-removed part of the ground motion.

Figure 4 compares the mean inelastic displacement ratios for the 65 pulse-like ground motions and the pulseremoved parts. It can be seen that when the predominant pulse is removed, the inelastic displacement ratios have clear decreases at a medium period region. Figure 4 also shows the regression results obtained by two previous studies. The results of Miranda did not consider the inelastic displacement ratios of pulse-like ground motions [34]. The results of Chopra and Chintanapakdee correspond to the ground motions in the group of magnitude $(6.6<M<6.9)$ and distance $(13<R<30 \mathrm{~km})$ [16]. Their results also did not include the effect of pulse-like ground motions. It can be seen that the mean inelastic displacement ratios of the pulseremoved parts are very close to the regression results for the inelastic displacement ratios of the non-pulse-like ground motions obtained by the two studies, especially for large ductility levels.

\section{Effects of Pulse Parameters on the Inelastic Displacement Ratios and the Relations with Other Parameters}

5.1. Effects of the Pulse Period on the Inelastic Displacement Ratios. The inelastic displacement ratios usually have a clear "bump" at the medium period region due to the influence of the predominant velocity pulse [19]. Previous studies have shown that the pulse period is an important parameter influencing the locations of the bump. Iervolino et al. [35] pointed out that the increments are displayed in a range of periods between about $30 \%$ and $50 \%$ of the pulse period. In this paper, the pulse period $T_{p}$ is defined as the period associated with the peak value of the velocity response spectrum of the extracted pulse. To analyze the influence of the pulse period, this paper selects $T_{p}=3 \mathrm{~s}, 4 \mathrm{~s}$, and $5 \mathrm{~s}$ as the threshold value separately and then divides the 65 pulse-like ground motions into two groups. Figure 5 shows the ratios of the mean inelastic displacement ratios for the two groups for each threshold value. It can be seen that the pulse period has significant effects on the inelastic displacement ratios. To further investigate the influence of the pulse period, this paper computes the ratio $(r)$ of the inelastic displacement ratios of the original ground motion to those of the corresponding pulse-removed part and then finds the period $T_{\mathrm{f}}$ associated with the peak value of $r$. Figure 6 shows the relations of $T_{\mathrm{f}}$ with the pulse period $T_{\mathrm{p}}$ and indicates that $T_{\mathrm{f}}$ is about $0.43 T_{\mathrm{p}}$. The results are used in Section 6 to develop the prediction equation of the inelastic displacement ratios of pulse-like ground motions.

The horizontal axis of the inelastic displacement ratio spectrum is usually normalized by the pulse period to eliminate the influence of the pulse period (Figure 7(a)). The inelastic displacement ratios for all ductility levels have a clear bump at $T / T_{p}=0.43$. As shown in Figure $7(\mathrm{~b})$, the bumps disappeared when the predominant pulse is removed. It can be used as evidence that the predominant pulse is the actual reason causing a clear bump in the region around $T / T_{p}=0.43$.

\subsection{Effects of the Pulse Intensity on the Inelastic Displacement} Ratios. Pulse intensity is an important parameter to describe the pulse feature of a pulse-like ground motion. In previous studies, PGV is usually selected as a parameter to represent the pulse intensity. However, PGV is the original ground motion parameter rather than a parameter of the predominant pulse. In Baker's work [27], the ratio of the energy of the pulse-removed part to the energy of the original ground motion was used as an important parameter to identify pulse-like ground motions. Zhai et al. [28] adopted the relative pulse energy $E_{p}$, which is the ratio of the energy of the pulse to the energy of the original ground motion, to classify a ground motion as pulse-like or non-pulse-like. Based on these previous studies, this paper adopts the ratio of the energy of the extracted pulse to the energy of the 

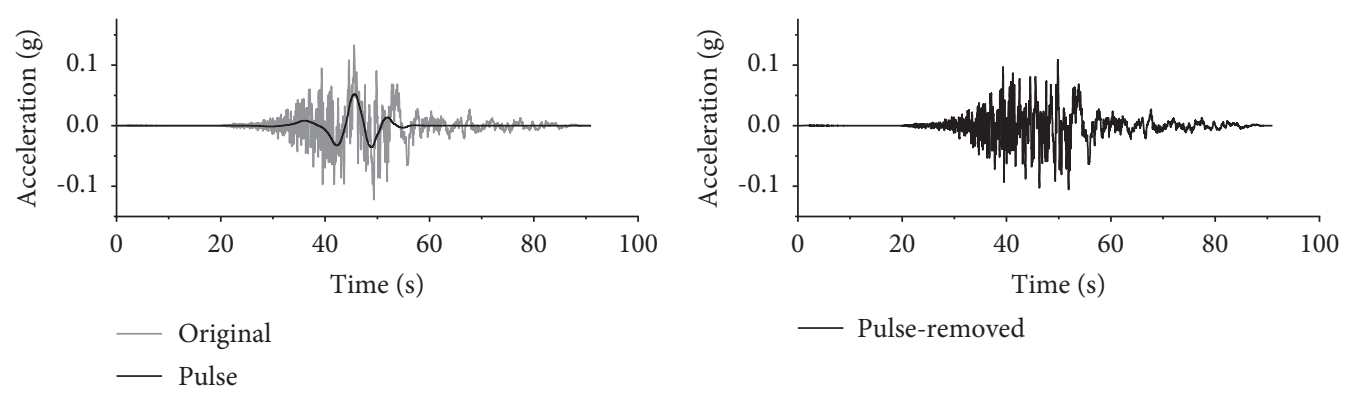

- Pulse-removed
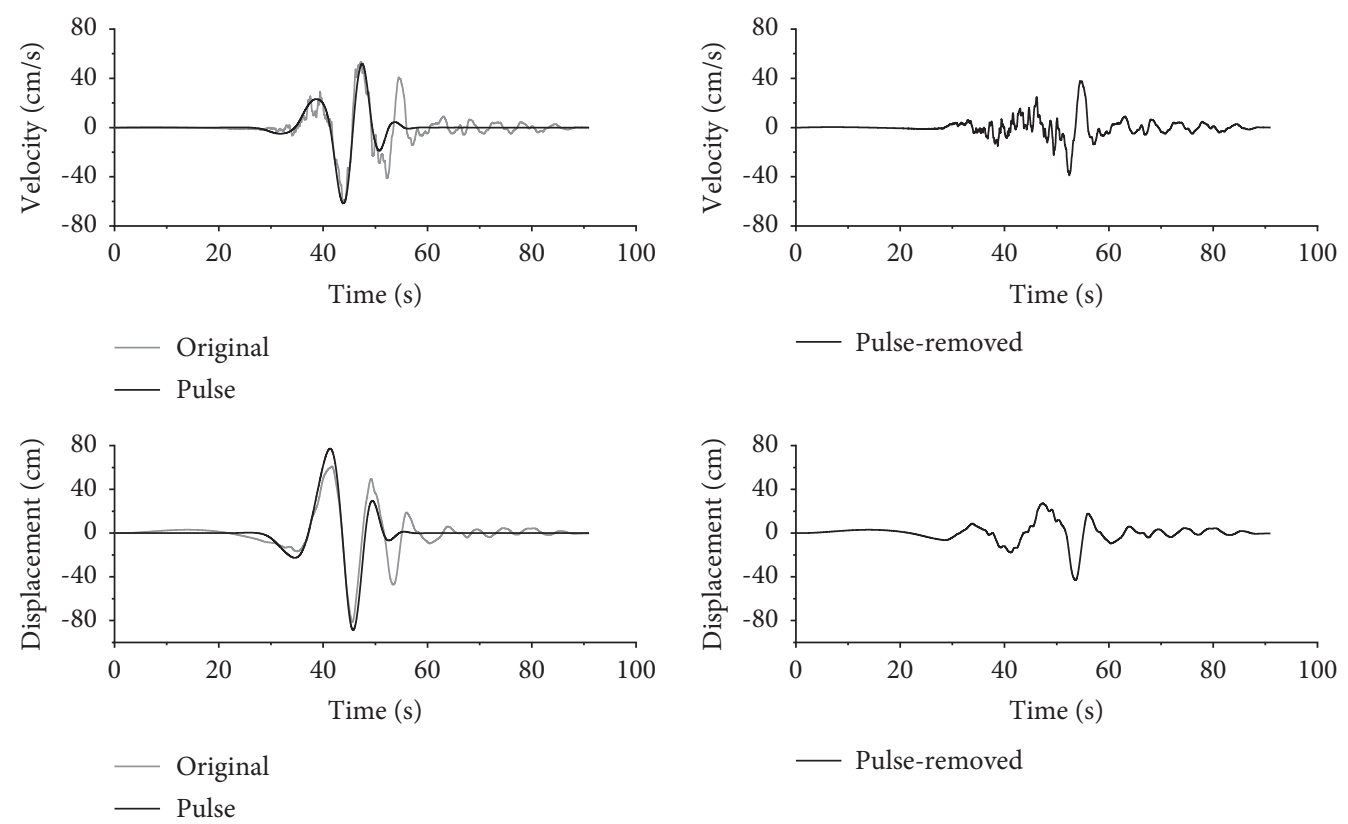

FIGURE 3: Time histories of the original ground motion, the extracted pulse, and the pulse-removed part of the ground motion recorded at TCU102 station during the 1999 Chi-Chi earthquake.
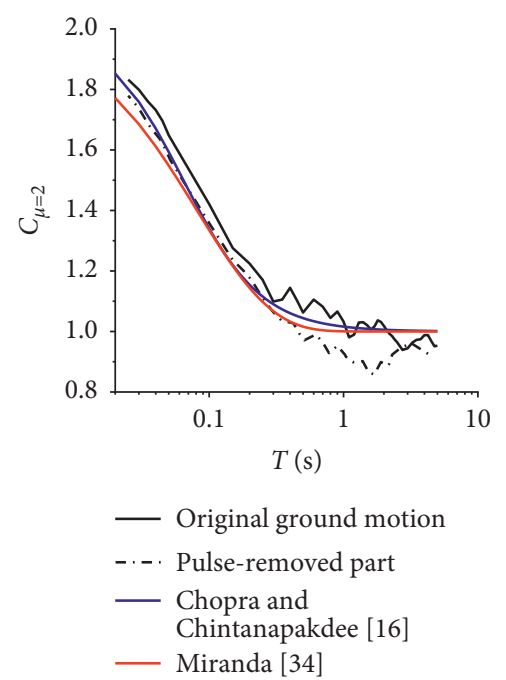

(a)

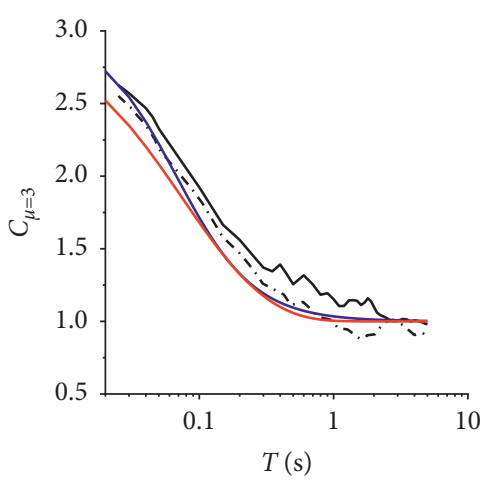

— Original ground motion

-. - . Pulse-removed part

- Chopra and Chintanapakdee [16]

— Miranda [34]

(b)

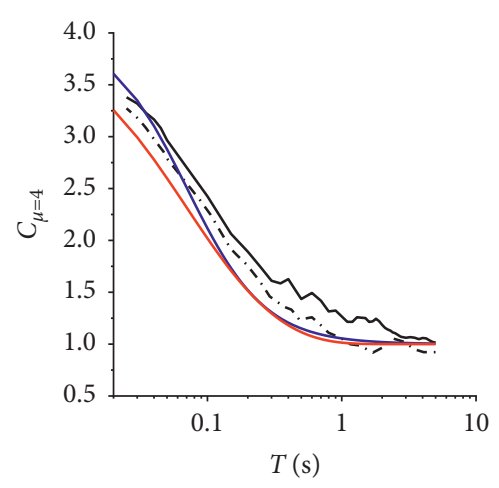

— Original ground motion
-.-. Pulse-removed part
— Chopra and
$\quad$ Chintanapakdee [16]
— Miranda [34]

(c)

FIGURE 4: Continued. 


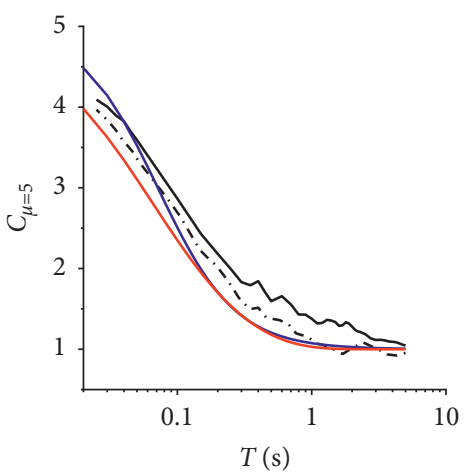

- Original ground motion

-... Pulse-removed part

- Chopra and Chintanapakdee [16]

— Miranda [34]

(d)

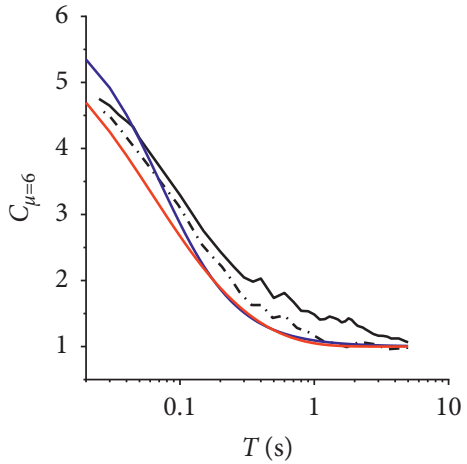

— Original ground motion

-.-. Pulse-removed part

- Chopra and Chintanapakdee [16]

— Miranda [34]

(e)

FIgURE 4: Comparison of the mean of the inelastic displacement ratios for the 65 original ground motions and the corresponding pulseremoved parts and the regression results of two previous studies for (a) $\mu=2$, (b) $\mu=3$, (c) $\mu=4$, (d) $\mu=5$, and (e) $\mu=6$.

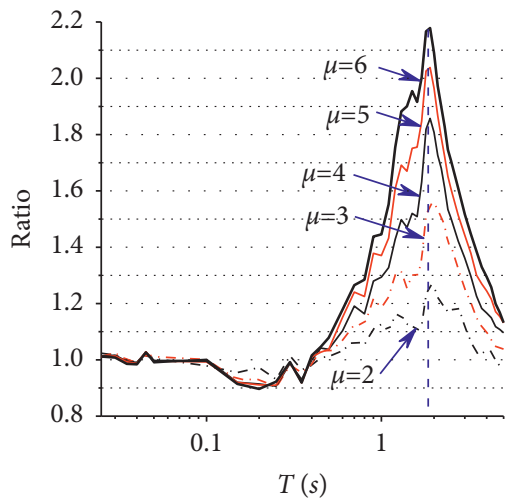

(a)

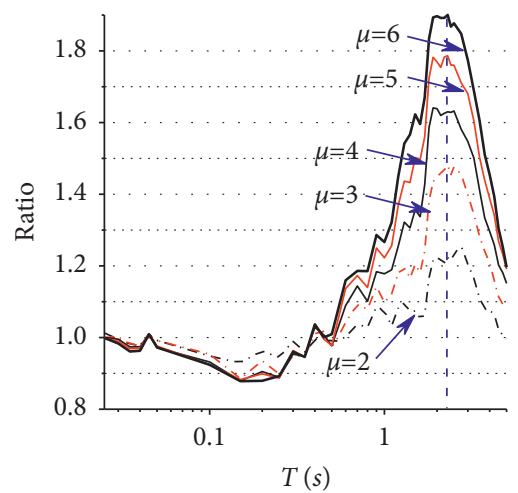

(b)

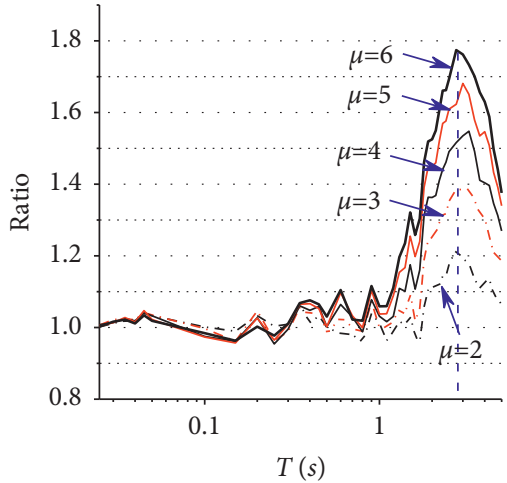

(c)

Figure 5: Ratios of the mean inelastic displacement ratios for (a) $C_{\mu}\left(T_{p}>3 \mathrm{~s}\right) / C_{\mu}\left(T_{p} \leq 3 \mathrm{~s}\right),(\mathrm{b}) C_{\mu}\left(T_{p}>4 \mathrm{~s}\right) / C_{\mu}\left(T_{p} \leq 4 \mathrm{~s}\right)$, and (c) $C_{\mu}\left(T_{p}>5 \mathrm{~s}\right) /$ $C_{\mu}\left(T_{p} \leq 5 \mathrm{~s}\right)$.
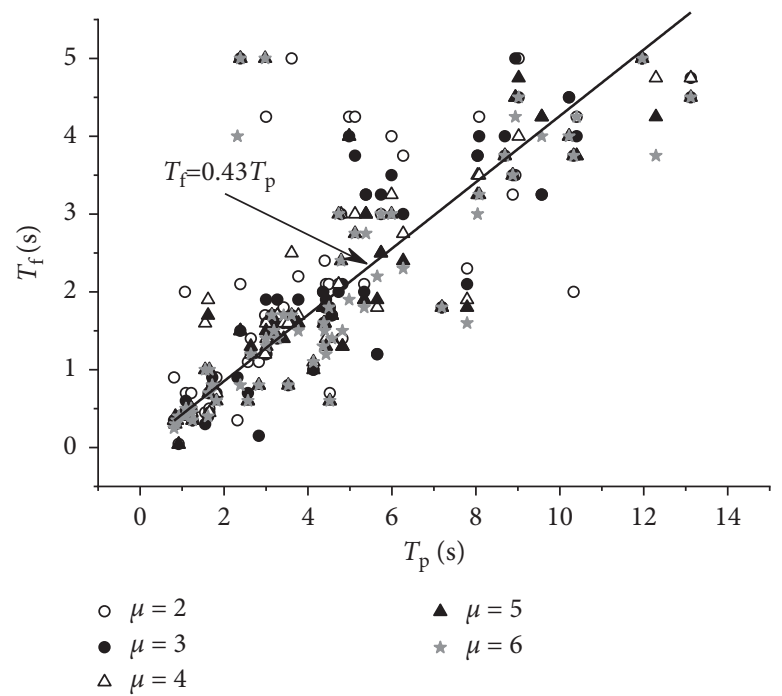

Figure 6: Scatter plot of $T_{f}$ to $T_{p}$. 


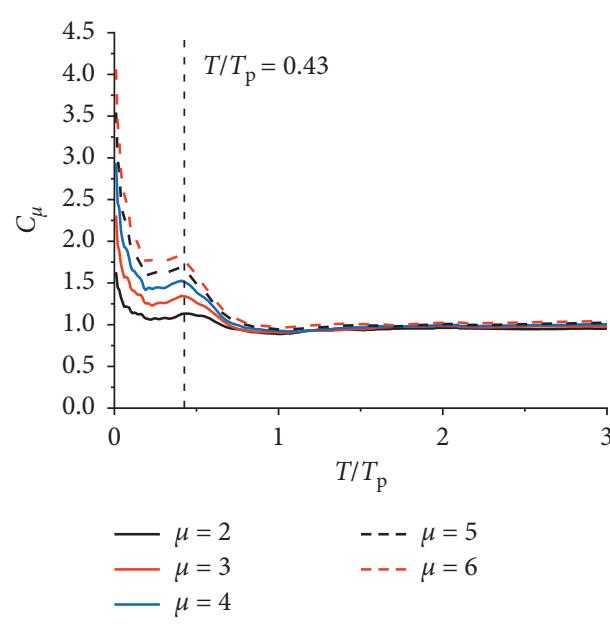

(a)

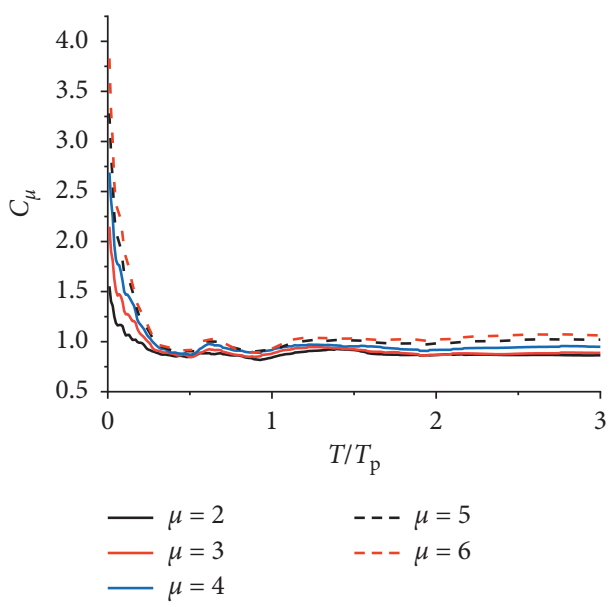

(b)

Figure 7: The mean inelastic displacement ratios for the (a) original ground motions and the (b) pulse-removed pars with the horizontal axis normalized by the pulse period $\left(T_{p}\right)$.

original ground motion as the pulse intensity and denotes it as PI, see the following equation:

$$
P I=\frac{\left(\sum_{i=1}^{N} V_{\text {Pulse }, i}^{2}\right)}{\sum_{i=1}^{N} V_{\text {Original }, i}^{2}},
$$

where $V_{\text {Pulse, } i}$ and $V_{\text {Original, } i}$ are the values of the velocity time-history for the extracted pulse and the original ground motion at the $i$ th point, respectively; and $N$ is the number of points of the ground motion time history.

Table 1 shows the values of PI for the 65 pulse-like ground motions. This paper divides the ground motions into three groups based on the value of PI, PI $\leq 0.55,0.55<$ $\mathrm{PI} \leq 0.7$, and $\mathrm{PI}>0.7$. Figure 8 shows the comparison of the ratios of the inelastic displacement ratios of the original ground motions to those of the pulse-removed parts for the three groups. It can be seen that the ratios of $C_{\text {Original }} / C_{\text {Pulse- }}$ removed are the largest at the point around $T / T_{p}=0.43$ and increase gradually with the increase of the pulse intensity PI and the ductility factor $\mu$. The maximum value of the ratios $C_{\text {Original }} / C_{\text {Pulse-removed }}$ is used to analyze the effect degree of PI on the inelastic ratios of pulse-like ground motions and is denoted as $r_{\max }$. As mentioned above, the inelastic displacement ratios are calculated at 45 periods for each ground motion. $r_{\max }$ is the maximum value among the 45 ratios of $C_{\text {Original }} / C_{\text {Pulse-removed }}$. Figure 9 shows the scatter plot of $r_{\max }$ (the maximum value of $C_{\text {Original }} / C_{\text {Pulse-removed }}$ ) to pulse intensity PI. It can be seen that pulse intensity is a crucial factor that can affect the degree of the increments of the inelastic displacement ratios. Besides, a higher ductility factor $\mu$ can lead to a larger $r_{\max }$. This paper adopts (4) to predict $r_{\max }$, where $\varepsilon$ is a random variable with zero mean and unit variance:

$$
\begin{aligned}
\ln \left(r_{\max }\right)= & 0.3+1.04 \ln (P I+0.6) \\
& +0.19 \ln (\mu-1)+0.02 \mu+0.22 \varepsilon .
\end{aligned}
$$

In (4), only the pulse intensity PI and the ductility factor $\mu$ are considered because the analysis indicates that other parameters (e.g., $T_{p}$, PGA, PGV, PGD, and Arias intensity $I_{\mathrm{a}}$ ) do not provide a significant contribution to the model of $r_{\max }$. It can also be verified by the analysis work of the following section (Section 5.3). The term $\ln (\mathrm{PI}+$ constant $)$ is used to avoid unrealistic predictions of $r_{\max }$ at the location of lower PI. The term $\ln (\mu-$ constant) is used to avoid unrealistic predictions of $r_{\max }$ at the location of lower $\mu$. The term $\mu$ is considered because the standard deviation has a clear increase when the term is removed. Figure 9 shows the regression results for three levels of ductility factor.

Figure 10 shows the scatter plot of pulse period $T_{p}$ to pulse intensity PI. The Pearson correlation coefficient between PI and $T_{p}$ is only 0.28 . Thus, the pulse period and the pulse intensity are two independent parameters. One controls the location on which the inelastic displacement ratio would have clear increments, and one controls the degree of the increments.

5.3. Effects of Other Commonly Used Parameters and Their Relations to the Pulse Period and the Pulse Intensity. Many parameters have been defined to describe a ground motion in the literature. Investigating the effects of the commonly used parameters on the inelastic displacement ratios of pulse-like ground motions is very meaningful in some relevant areas, such as the ground motion selection for the seismic design of structures in the near-fault zone. This section investigates the effects of five commonly used parameters, PGV, PGD, PGV/PGA, Arias intensity $I_{\mathrm{a}}$, and soil conditions on the inelastic displacement ratios of pulse-like ground motions and their relations to the pulse period and the pulse intensity. The Arias intensity $\left(I_{\mathrm{a}}\right)$ is defined as follows: 


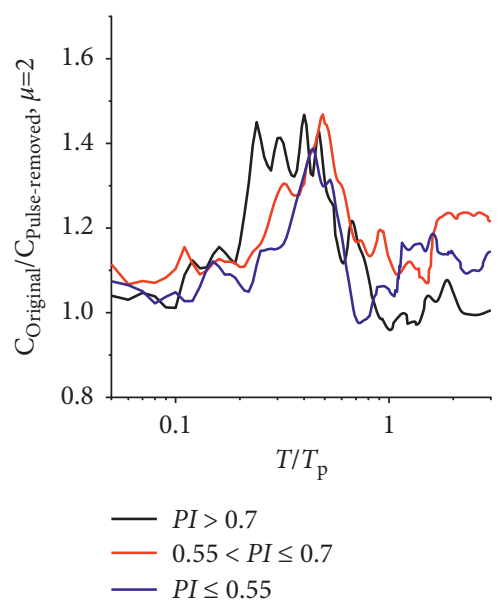

(a)

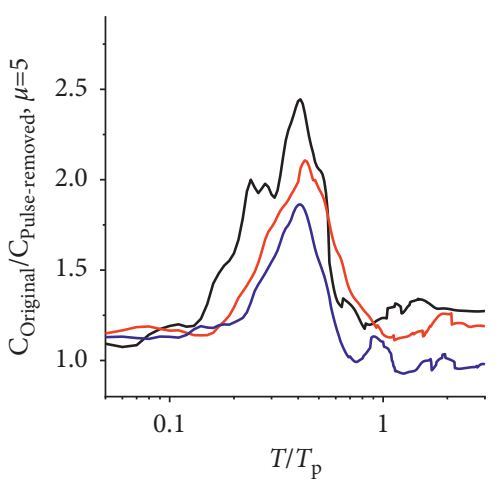

$$
\begin{aligned}
& -P I>0.7 \\
& -0.55<P I \leq 0.7 \\
& -P I \leq 0.55
\end{aligned}
$$

(d)
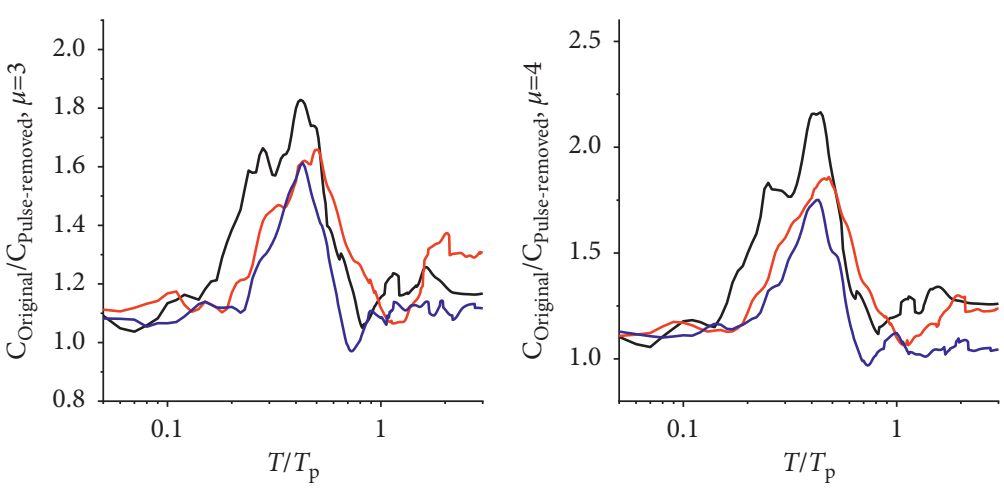

$P I>0.7$
$-\quad 0.55<P I \leq 0.7$
$-P I \leq 0.55$

$-P I>0.7$

$-0.55<P I \leq 0.7$

$-P I \leq 0.55$

(b)

(c)

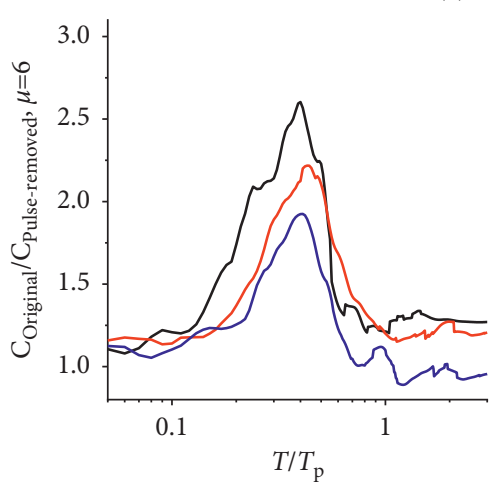

- $P I>0.7$

$-0.55<P I \leq 0.7$

PI $\leq 0.55$

(e)

Figure 8: Comparison of the ratios for the inelastic displacement ratios between the original ground motions and the pulse-removed parts for (a) $\mu=2$, (b) $\mu=3$, (c) $\mu=4$, (d) $\mu=5$, and (e) $\mu=6$.

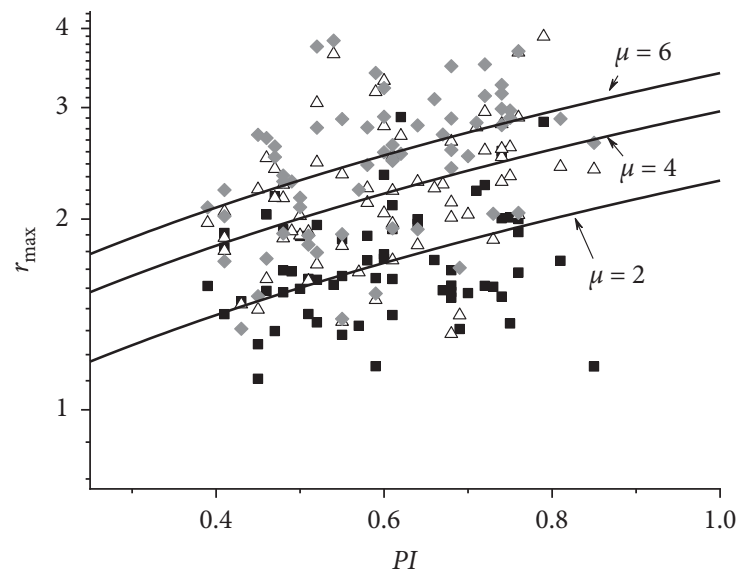

$$
\begin{aligned}
\text { - } \mu & =2 \\
\triangle \mu & =4 \\
-\mu & =6
\end{aligned}
$$

FIgURE 9: Scatter plot of the maximum ratio $r_{\max }$ to pulse intensity PI for $\mu=2,4$, and 6. 


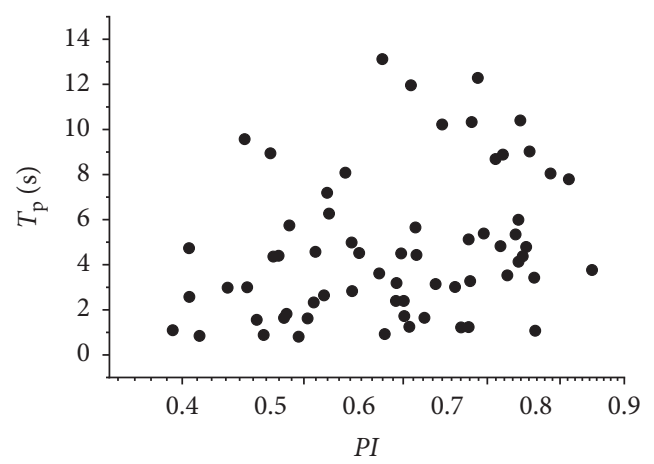

Figure 10: Scatter plot of the pulse period $T_{p}$ to the pulse intensity PI.

$$
I_{\mathrm{a}}=\frac{\pi}{2 g} \int_{0}^{T_{\mathrm{d}}}[\ddot{X}(t)]^{2} \mathrm{~d} t,
$$

where $\ddot{X}(t)$ is the acceleration time history of a ground motion, $T_{d}$ is the total duration of the motion, and $g$ is the acceleration of gravity.

Similar to the analysis of the pulse period in Figure 7, to investigate the effects of these parameters on the inelastic displacement ratios, the 65 ground motions are divided into two groups for each parameter, greater and less than the threshold value of the parameter. The threshold values of PGV, PGD, PGV/PGA, and $I_{\mathrm{a}}$ are $70 \mathrm{~cm} / \mathrm{s}, 40 \mathrm{~cm}, 0.2 \mathrm{~s}$, and $2 \mathrm{~m} / \mathrm{s}$, respectively. Soil condition is divided into stiff soil (consistent with the NEHRP soil classification of B and C) and soft soil (consistent with the NEHRP soil classification of $D$ and E). This paper computes the ratios between the mean inelastic displacement ratios of the ground motions for the two groups for each parameter (see Figure 11). It can be seen that (a) PGV/PGA and PGD cause significant effects on the inelastic displacement ratios of pulse-like ground motions; (b) $I_{\mathrm{a}}$ and soil condition have obvious effects on the inelastic displacement ratios at long periods; (c) compared to other parameters, the effects caused by PGV are insignificant.

Yaghmaei-Sabegh [17] also investigated the influence of the same set of ground motion parameters on the inelastic displacement ratios of pulse-like ground motions. The analysis results of this paper are generally consistent with those of Yaghmaei-Sabegh [17]. In this paper, the ratios of $C_{\mu}\left(I_{a}>2 \mathrm{~m} / \mathrm{s}\right) / C_{\mu}\left(I_{a} \leq 2 \mathrm{~m} / \mathrm{s}\right)$ are less than 1 in the long periods. However, the ratios are greater than 1 in the long periods in Yaghmaei-Sabegh's work [17]. Thus, when a different set of ground motions is selected, the effects caused by some ground motion parameters on the inelastic displacement ratios of pulse-like ground motions might have obvious changes. This will cause controversy and will hinder the application of some relevant research achievements on the seismic design of structures. PGV/PGA, to an extent, is a period parameter. The pulse-like ground motion with a longer pulse period will be more likely to have a larger PGD. Mavroeidis et al. [36] indicated that PGV/PGA and PGD are related to the pulse period. It is easy to conjecture that the reason why some parameters can cause significant effects on the inelastic displacement ratios of pulse-like ground motions is because these parameters are strongly related to the pulse period. The ratios shown in Figure 5 are much greater than those in Figure 11. Thus, the pulse period can cause more significant influences on the inelastic displacement ratios.

Figure 12 shows the relations of the five parameters to the pulse period. The Pearson correlation coefficients between PGV and $T_{\mathrm{p}}$, PGD and $T_{\mathrm{p}}$, PGV/PGA and $T_{\mathrm{p}}, I_{\mathrm{a}}$, and $T_{\mathrm{p}}$, and $V_{\mathrm{s}, 30}$ and $T_{\mathrm{p}}$ are $0.11,0.60,0.68,-0.33$, and -0.1 , respectively. By comparing Figures 12 and 11, we can see that PGD and PGV/PGA increase gradually with the increase of pulse period. It is the main reason why the ratios are greater than 1 in the long periods in Figures 12(b) and 12(c). There are more ground motions with a large pulse period in the group of $I_{a} \leq 2 \mathrm{~m} / \mathrm{s}$. As a result, the ratios are less than 1 in the long periods in Figure 11(d). Such an explanation can also be used for Figures 11(a) and 11(e). Thus, using the pulse period can make an interpretation for the effects caused by the five parameters on the inelastic displacement ratios of pulse-like ground motions. If one parameter is positively related to the pulse period, then the inelastic displacement ratios of a ground motion with a higher level of the parameter have clear increments at long periods. If it is negatively related, the increments occur in short periods. Arias intensity does not have apparent relations with the pulse period. When a different set of ground motions is selected, its influence on the inelastic displacement ratios may have some changes.

It is also important to investigate the effects of the five parameters on the degree of the increments. Similar to the analysis of the pulse intensity in Figure 8, this paper divides the 65 pulse-like ground motions into 3 groups for each parameter and then compares the mean ratios of $C_{\text {Original }} /$ $C_{\text {Pulse-removed }}$ Figure 13 shows the results when $\mu=6$. The ratios of $C_{\text {Original }} / C_{\text {Pulse-removed }}$ shown in Figure 13 are less than those in Figure 8. It means that the influence of the five parameters on the degree of the increments of the inelastic displacement ratios in the region around $T / T_{\mathrm{p}}=0.43$ is less significant than that caused by the pulse intensity PI. As stated above, PGV/PGA is the most correlated one to the pulse period for the five parameters. However, it does not affect the degree of the increments of the inelastic displacement ratios in the region around $T / T_{p}=0.43$ (see 


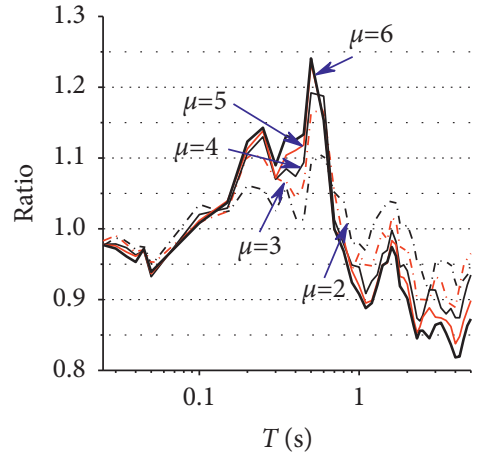

(a)

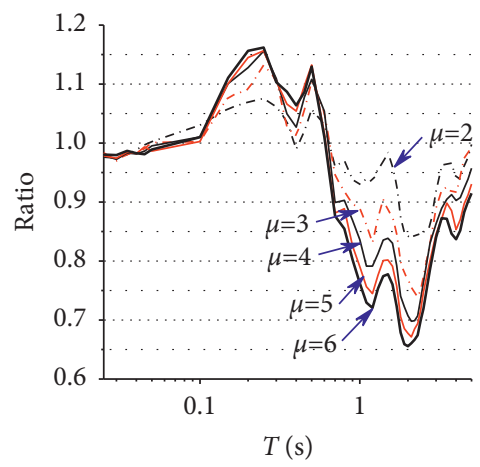

(d)

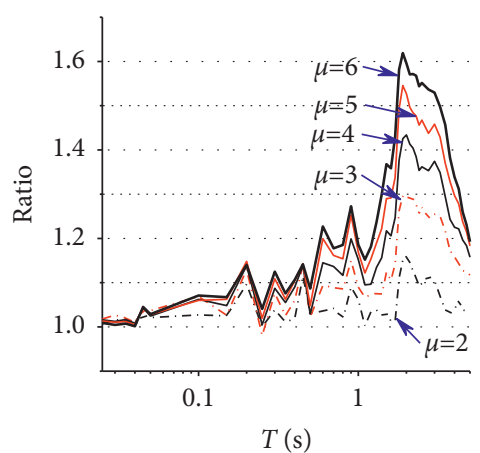

(b)

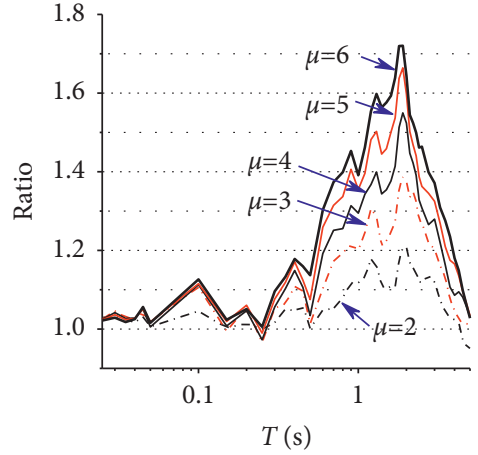

(c)

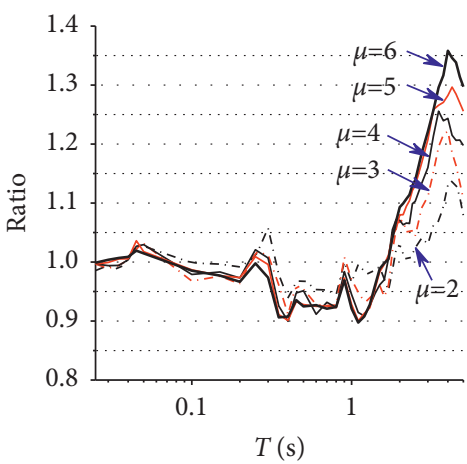

(e)

Figure 11: Ratios of the mean inelastic displacement ratios for (a) $C_{\mu}(\mathrm{PGV}>70 \mathrm{~cm} / \mathrm{s}) / C_{\mu}(\mathrm{PGV} \leq 70 \mathrm{~cm} / \mathrm{s})$, (b) $C_{\mu}(\mathrm{PGD}>40 \mathrm{~cm}) /$ $C_{\mu}(\mathrm{PGD} \leq 40 \mathrm{~m}),(\mathrm{c}) C_{\mu}(\mathrm{PGV} / \mathrm{PGA}>0.2 \mathrm{~s}) / C_{\mu}(\mathrm{PGV} / \mathrm{PGA} \leq 0.2 \mathrm{~s}),(\mathrm{d}) C_{\mu}\left(I_{a}>2 \mathrm{~m} / \mathrm{s}\right) / C_{\mu}\left(I_{a} \leq 2 \mathrm{~m} / \mathrm{s}\right)$, and (e) $C_{\mu}\left(\right.$ Stiff Soil) $/ C_{\mu}($ soft soil).

Figure 13(c)). In previous studies, PGV is usually selected as the parameter to represent the pulse intensity. In Figure 13(a), a larger PGV would like to result in smaller inelastic displacement ratios in the region around $T /$ $T_{p}=0.43$, which is contrary to our cognition. The Pearson correlation coefficients between PGV and PI, PGD and PI, PGV/PGA and PI, $I_{a}$ and PI, and $V_{s, 30}$ and PI are $-0.10,0.16$, $0.36,-0.43$, and -0.18 , respectively. All five parameters are not clearly correlated with the pulse intensity PI. $I_{a}$ is more clearly negatively correlated with PI, so a larger $I_{a}$ would like to result in smaller inelastic displacement ratios in the region around $T / T_{p}=0.43$.

It can be concluded that the pulse period and the pulse intensity are two nearly independent parameters that can cause a significant influence on the inelastic displacement ratios of pulse-like ground motions. The pulse period determines the locations on which the inelastic displacement ratios have clear increments, and the pulse intensity determines the degree of the increments. The influence of other parameters on the inelastic displacement ratios can be explained by their relations to the pulse period and the pulse intensity.

\section{Equations for the Mean Inelastic Displacement Ratios}

For the convenience of engineering applications, it is necessary and desirable to propose a prediction model for the mean inelastic displacement ratios of pulse-like ground motions. As stated above, the pulse intensity can highly affect the amplitude of the bumps of the inelastic displacement ratios at the points around $T / T_{p}=0.43$. However, this phenomenon has not been considered in previous studies. Based on the prediction models of previous studies $[22,23]$, this paper adopts (6) to predict the mean inelastic displacement ratios of pulse-like ground motions:

$$
\widetilde{C}_{\mu}=1+\left[\frac{1}{\mu-1}+\left(\frac{146.9}{\mu^{2.5}}+3.3\right)\left(\frac{T}{T_{p}}\right)^{0.8}\right]^{-1}-0.05 \mu^{0.77} e^{-4.7\left[\log \left(T / T_{p}\right)-0.12\right]^{2}}+0.15 r_{\max } e^{-8.2\left[\log \left(T / T_{p}\right)+0.85\right]^{2}}
$$

In (6), the first two terms are used to capture the overall trend of the inelastic displacement ratios, which is similar to the model of Chopra and Chintanapakdee [16].
The third term is the probability density function of a logarithmic normal distribution and is used to capture the local reduction in the region around $T / T_{p}=1$. The last 


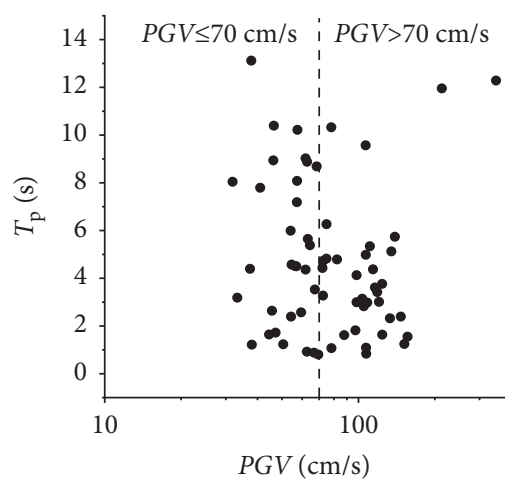

(a)

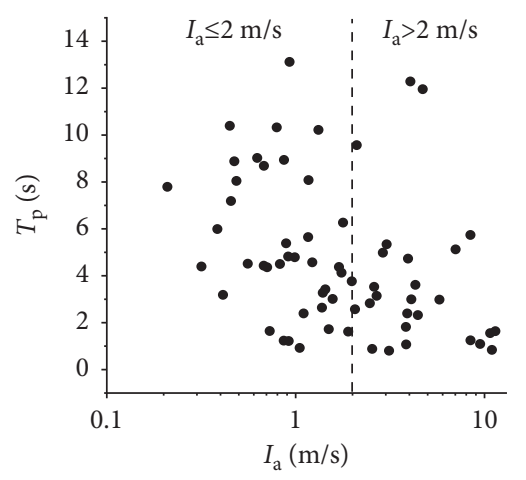

(d)

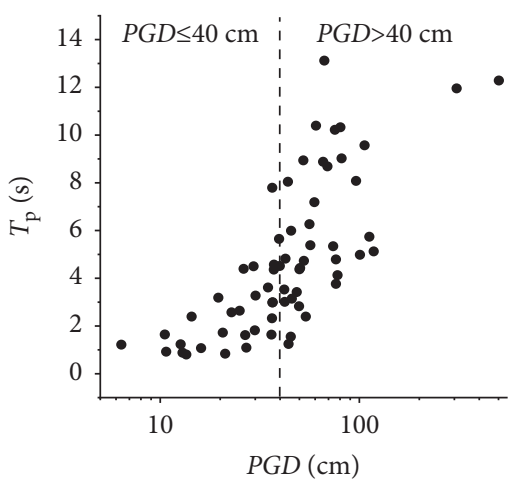

(b)

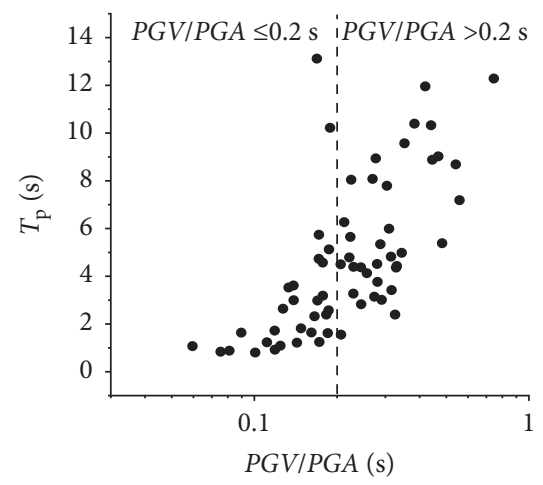

(c)

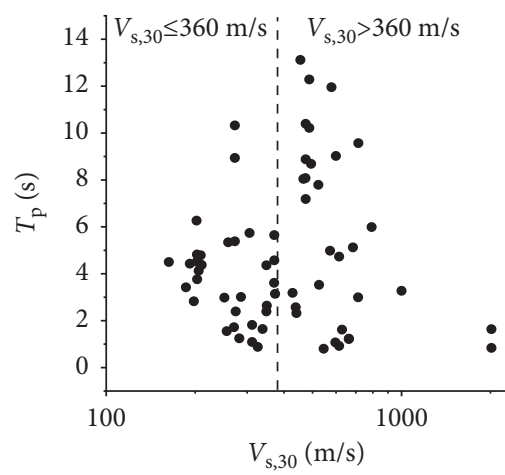

(e)

FIgUre 12: Scatter plot of (a) PGV, (b) PGD, (c) PGV/PGA, (d) $I_{a}$, and (e) $V_{s, 30}$ to the pulse period $T_{p}$.

term is used to capture the feature of the local increments in the region around $T / T_{p}=0.43$. The amplitude of the increments is controlled by $r_{\max }$, which is the maximum ratio for the inelastic displacement ratios between the original ground motion and the pulse-removed part, as defined early. As given in (4), $r_{\max }$ is affected by the pulse intensity and the ductility factor. Thus, the influence of the pulse intensity is included in the prediction model. In the regression process, the values of the parameters of the first two terms are determined first, and the values of the parameters of the third term are determined by using the residuals. Finally, the values of the parameters of the last term are determined by using the new residuals. Subjective judgments are unavoidable in selecting the prediction model because the process is guided by the inspection of the data, the residuals, and the characteristics of different prediction models. Figure 14 compares the regression results to the mean inelastic displacement ratios. It can be seen that the prediction equation is efficient in capturing the main feature of the mean inelastic displacement ratios of pulse-like ground motions. However, the inelastic displacement ratios estimated by the regression equation are clearly greater than the mean values in the region around $T / T_{p}=0.43$ when $\mu=2$. It is caused by the less-accurate consideration of the influence of the ductility factor in equation (4). Because the influence of the ductility factor on $r_{\max }$ is nonlinear, it is difficult to capture the feature by using logarithmic functions when the ductility factor is lower.
It should be noted that (6) just provides the mean estimation and does not give the random term because the dispersion of the residual errors between the real inelastic displacement ratios and the mean estimates varies at different $T / T_{p}$ locations. Figure 15 shows the scatter plot of the residual errors between the real displacement ratios and values estimated by the proposed prediction equation to $\mathrm{T} /$ $T_{p}$. It can be seen that the residual errors nearly vibrate around the axis of $y=0$; however, the standard deviation (dispersion) of the residual errors varies at different locations. A similar phenomenon has been reported by previous studies, such as the study of Ruiz-García and Miranda [23]. As shown in (6), the inelastic displacement ratio also relies on the value of $r_{\max }$. According to (4), $r_{\max }$ is a random variable and relies on the value of pulse intensity PI. This paper does not give the prediction model of PI because the relationship between pulse intensity and other parameters is not clear. If more pulse-like ground motions are collected in the future, the prediction model of pulse intensity might be developed. According to the information in Table 1, the smallest value of PI of the select pulse-like ground motions is 0.39 , and the largest value is 0.85 , the mean value of PI is 0.6 , and the median value of PI is also 0.6. If the detailed information of the pulse intensity is available, the mean (median) value, $\mathrm{PI}=0.6$, is suggested to be used as the input to estimate the mean of $r_{\max }$, and then use it to estimate the mean of the inelastic displacement ratios.

In the literature, the inelastic displacement ratios have been widely used in the estimation of the inelastic seismic demand of 

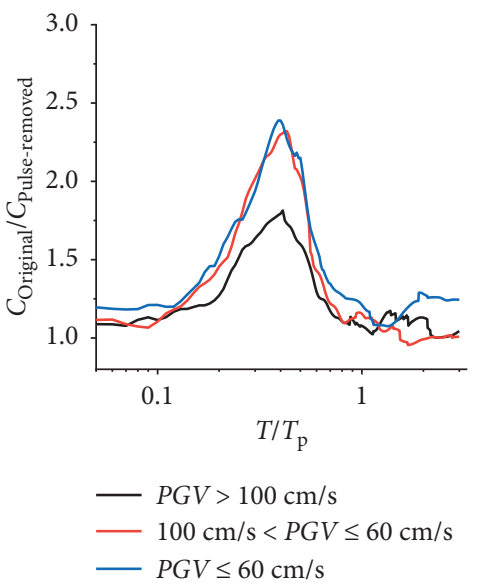

(a)

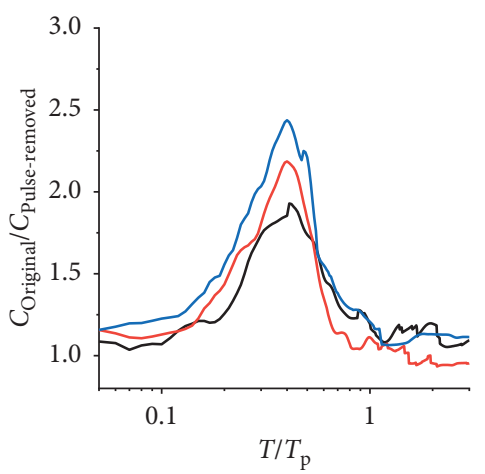
$-I_{\mathrm{a}}>2.5 \mathrm{~m} / \mathrm{s}$
$1 \mathrm{~cm}<I_{\mathrm{a}} \leq 2.5 \mathrm{~m} / \mathrm{s}$ $-I_{\mathrm{a}} \leq 1 \mathrm{~m} / \mathrm{s}$

(d)

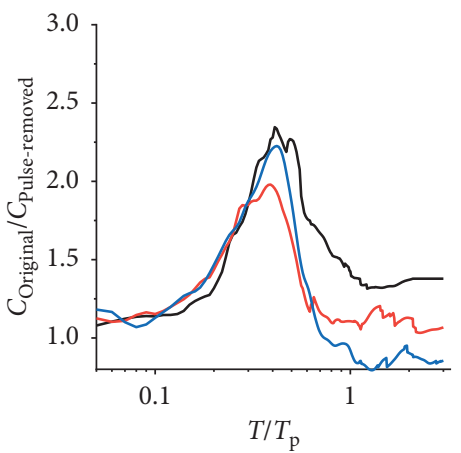

$$
\begin{aligned}
& -P G D>55 \mathrm{~cm} \\
& -35 \mathrm{~cm}<P G D \leq 55 \mathrm{~cm} \\
& -P G D \leq 35 \mathrm{~cm}
\end{aligned}
$$

(b)

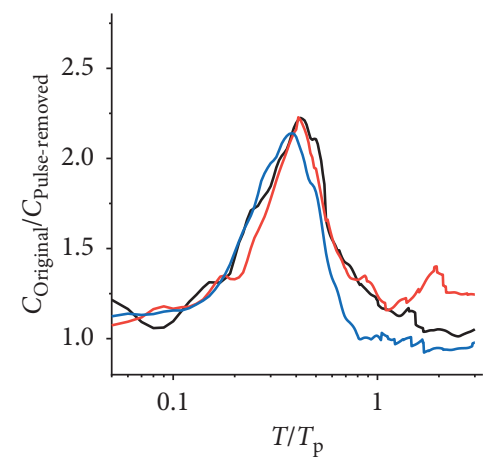

$$
\begin{array}{ll}
- & V_{\mathrm{s}, 30}>500 \mathrm{~m} / \mathrm{s} \\
- & 300 \mathrm{~m} / \mathrm{s}<V_{\mathrm{s}, 30} \leq 500 \mathrm{~m} / \mathrm{s} \\
- & V_{\mathrm{s}, 30} \leq 300 \mathrm{~m} / \mathrm{s}
\end{array}
$$

(e)

Figure 13: Comparison of the mean ratios of the inelastic displacement ratios $(\mu=6)$ for the original ground motions to those of the pulseremoved parts for the recordings in different (a) PGV, (b) PGD, (c) PGV/PGA, (d) $I_{a}$, and (e) $V_{s, 30}$ groups.
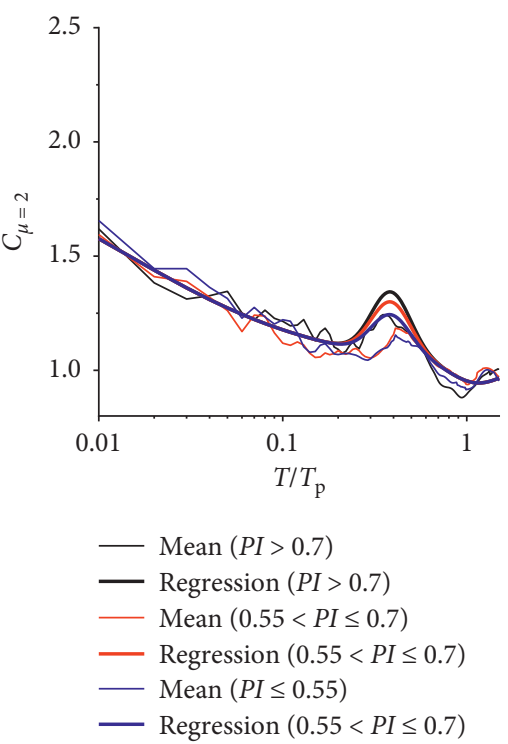

(a)

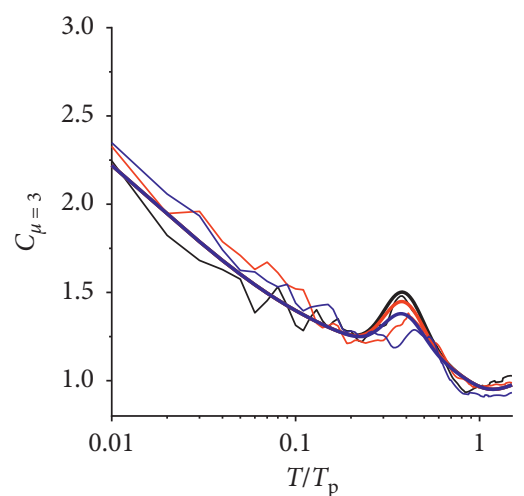

Mean $(P I>0.7)$

Regression $(P I>0.7)$

Mean $(0.55<P I \leq 0.7)$

Regression $(0.55<P I \leq 0.7)$

Mean $(P I \leq 0.55)$

- Regression $(0.55<P I \leq 0.7)$

(b)
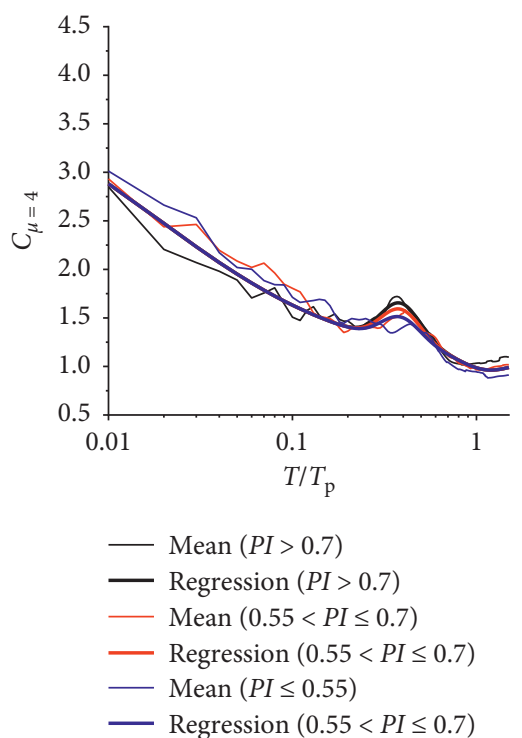

(c)

Figure 14: Continued. 


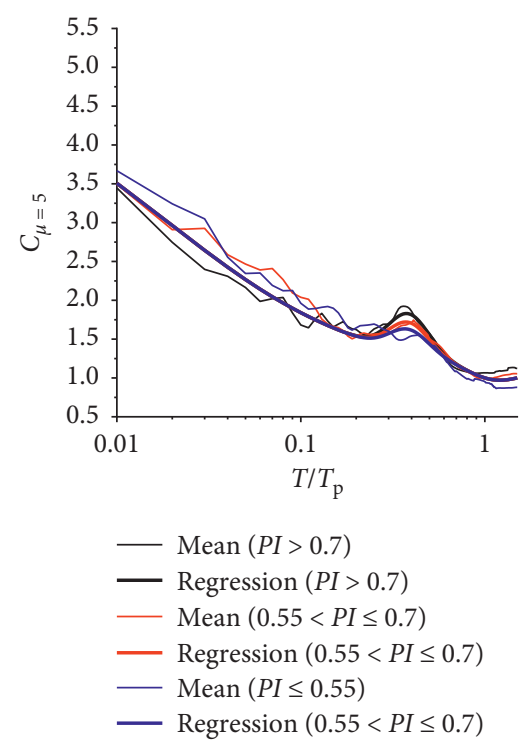

(d)

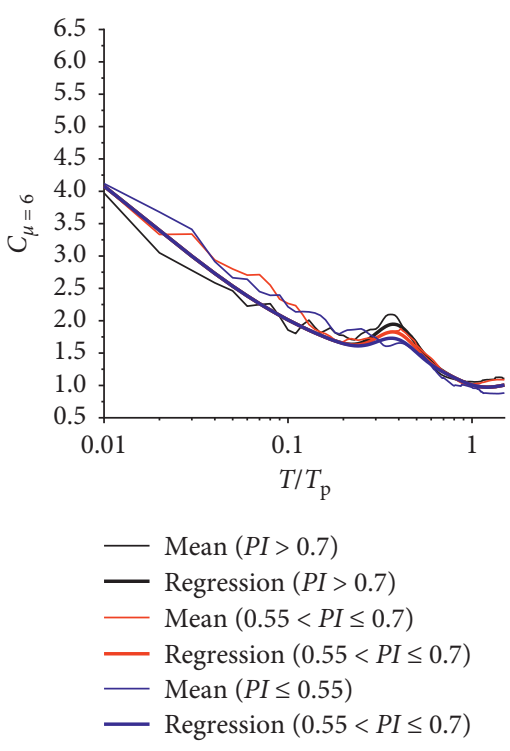

(e)

Figure 14: Comparison of the regression results to the mean inelastic displacement ratios for (a) $\mu=2$, (b) $\mu=3$, (c) $\mu=4$, (d) $\mu=5$, and (e) $\mu=6$.

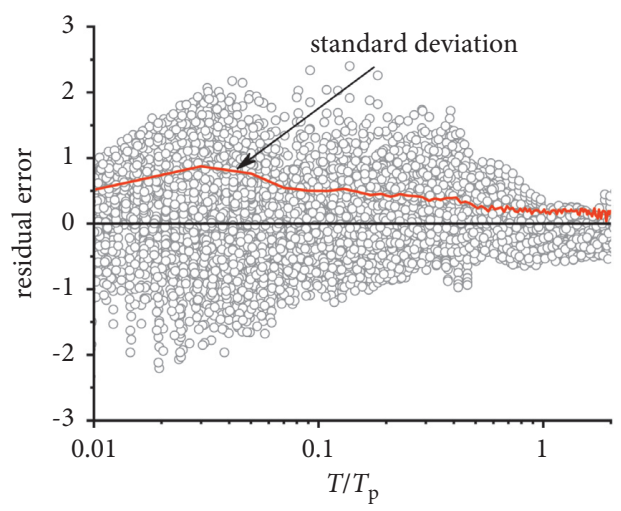

FIGURE 15: Scatter plot of the residual errors between the real displacement ratios and values estimated by the proposed prediction equation to $T / T_{p}$.

structures. The constant-strength inelastic displacement ratios play an important role in the displacement coefficient method (DCM), which is a convenient method to estimate the lateral displacement demand of structures for the seismic rehabilitation of existing buildings and has been incorporated in the ASCE/SEI 41-17 standards [37]. The prediction equations of the inelastic displacement ratios for pulse-like ground motions proposed by previous studies have been adopted or examined to estimate the seismic demand of structures to pulse-like ground motions $[38,39]$. The constant-ductility inelastic displacement ratios are vital in the design of new structures for displacement-based design procedures, such as the so-called displacement-based design via inelastic displacement ratio approach [40]. Thus, a prediction model that reflects real characteristics of the inelastic displacement ratios of pulse-like ground motions is of great significance in engineering practice.
To show the characteristics of the proposed prediction equation, this section shows an application of using the proposed prediction equation to estimate the inelastic displacement ratios and makes a comparison to the results of real pulse-like ground motions. As a moderate level, PI is assumed as 0.6 , and the ductility factor $\mu$ is assumed as 4 . As given in Table 1, the PIs of the no. 3 and no. 5 ground motions are about 0.6 . Figure 16 shows the comparison of the inelastic displacement ratios of the two ground motions to the results of the prediction equation. It can be seen that the proposed prediction equation is feasible and is efficient in capturing the main feature of the inelastic displacement ratios of pulse-like ground motions, and the location and amplitude of the local bumps are generally consistent with the results of real pulse-like ground motions. 


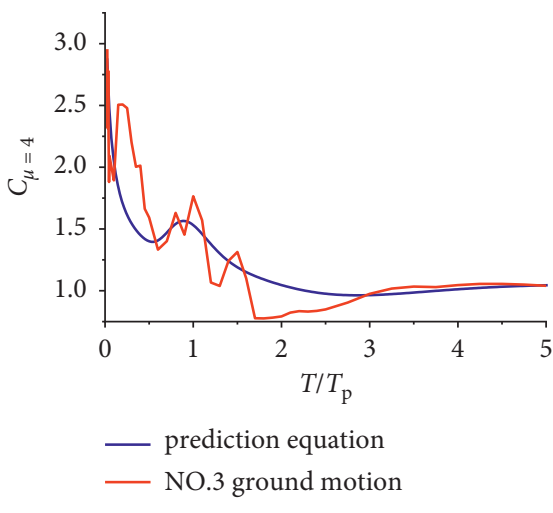

(a)

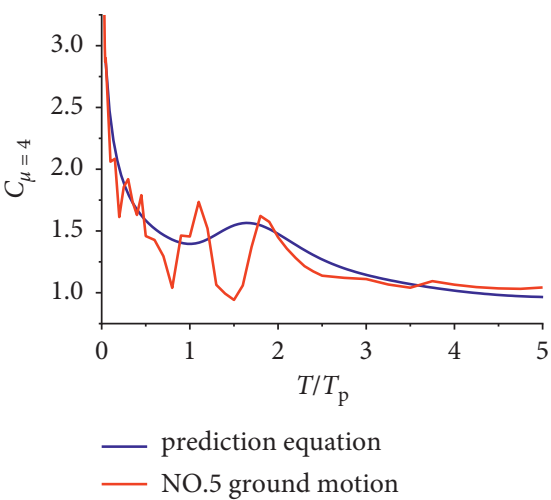

(b)

Figure 16: Comparison of the inelastic displacement ratios estimated by the proposed prediction equation to those of (a) no. 3 ground motion and (b) no. 5 ground motion of Table 1.

\section{Conclusions}

This paper presents a comprehensive study on the characteristics of the inelastic displacement ratios of pulse-like ground motions. This study leads to the following conclusions:

(1) The inelastic displacement ratios of pulse-like ground motions will have apparent increments at medium periods. The pulse period $T_{p}$ is an essential parameter of controlling the locations of the increments, around $0.43 T_{p}$, and the pulse intensity PI is a crucial factor influencing the degree of the increments. This paper adopts the ratio of the energy of the extracted pulse to the energy of the original ground motion as the pulse intensity. The analysis results indicate that $T_{p}$ and PI are (can be considered as) two independent parameters because the Pearson correlation coefficient between the two parameters is only 0.28 . When the predominant pulse is removed, the inelastic displacement ratios of the pulse-removed parts are close to those of non-pulse-like ground motions.

(2) The influence of PGV, PGD, PGV/PGA, Arias intensity $I_{\mathrm{a}}$, and soil condition on the inelastic displacement ratios can be explained by their relations to the pulse period and the pulse intensity. PGV/PGA is clearly positively related to the pulse period. However, it does not have clear relations to the pulse intensity. As a result, a larger value of PGV/PGA would result in larger inelastic displacement ratios at long periods, but PGV/PGA cannot clearly affect the degree of the increments. $I_{\mathrm{a}}$ is negatively correlated with the pulse intensity, so a larger $I_{a}$ would like to result in smaller inelastic displacement ratios in the region around $T /$ $T_{p}=0.43$. $\mathrm{PGV}$ is usually selected as the parameter to represent the pulse intensity. However, the results indicate that a larger PGV would like to result in smaller inelastic displacement ratios in the region around $T / T_{p}=0.43$ because the Pearson correlation coefficient between PGV and PI is -0.1 .
(3) To facilitate the use in practice, a new regression model is proposed to estimate the inelastic displacement ratios. Compared to previous models, the influence of the pulse intensity on the increments of the inelastic displacement ratios at the periods around $0.43 T_{p}$ is included in the model. The prediction equation is efficient in capturing the main feature of the mean inelastic displacement ratios. The degree of the increments is also influenced by the ductility factor $\mu$. It is difficult to capture the feature influenced by $\mu$ when $\mu$ is lower. As a result, the regression results are greater than the mean values of the inelastic displacement ratios in the region around $T / T_{p}=0.43$ when $\mu=2$.

\section{Data Availability}

All data and codes generated or used during the study are available from the corresponding author upon request.

\section{Conflicts of Interest}

The authors declare that they have no conflicts of interest regarding the publication of this paper.

\section{Acknowledgments}

This research was supported by the National Natural Science Foundation of China (51908169), National Natural Science Foundation of China Joint Fund Project (U2139207), and Local Science and Technology Development Foundation Guided by the Central Government (YDZX20203700001129). These are gratefully acknowledged.

\section{References}

[1] M. J. N. Priestley, G. M. Calvi, and M. J. Kowalsky, Displacement-Based Seismic Design of Structures, IUSS Press, Pavia, Italy, 2007.

[2] P. J. Stafford, T. J. Sullivan, and D. Pennucci, "Empirical correlation between inelastic and elastic spectral displacement demands," Earthquake Spectra, vol. 32, no. 3, pp. 1419-1448, 
2016.

[3] C. Durucan and A. R. Durucan, "Ap/Vp specific inelastic displacement ratio for the seismic response estimation of SDOF structures subjected to sequential near fault pulse type ground motion records," Soil Dynamics and Earthquake Engineering, vol. 89, pp. 163-170, 2016.

[4] E. Demirol and A. S. Ayoub, "Inelastic displacement ratios of SSI systems," Soil Dynamics and Earthquake Engineering, vol. 96, pp. 104-114, 2017.

[5] C. Durucan and M. Gümüş, "Direct use of peak ground motion parameters for the estimation of inelastic displacement ratio of SDOF systems subjected to repeated far fault ground motions," Earthquake Engineering and Engineering Vibration, vol. 17, no. 4, pp. 771-785, 2018.

[6] P. G. Somerville, N. F. Smith, R. W. Graves, and N. A. Abrahamson, "Modification of empirical strong ground motion attenuation relations to include the amplitude and duration effects of rupture directivity," Seismological Research Letters, vol. 68, no. 1, pp. 199-222, 1997.

[7] L. Jiang, J. Zhong, M. He, and W. Yuan, "Optimal seismic intensity measure selection for isolated bridges under pulselike ground motions," Advances in Civil Engineering, vol. 2019, Article ID 3858457, 22 pages, 2019.

[8] J. Yang, P. Li, H. Jing, and M. Gao, "near-fault ground motion influence on the seismic responses of a structure with viscous dampers considering SSI effect," Advances in Civil Engineering, vol. 2021, Article ID 6649124, 20 pages, 2021.

[9] V. Phan, M. S. Saiidi, J. Anderson, and H. Ghasemi, "Nearfault ground motion effects on reinforced concrete bridge columns," Journal of Structural Engineering, vol. 133, no. 7, pp. 982-989, 2007.

[10] R. Sehhati, A. Rodriguez-Marek, M. ElGawady, and W. F. Cofer, "Effects of near-fault ground motions and equivalent pulses on multi-story structures," Engineering Structures, vol. 33, no. 3, pp. 767-779, 2011.

[11] R. S. Jalali, M. Bahari Jokandan, and M. D. Trifunac, "Earthquake response of a three-span, simply supported bridge to near-field pulse and permanent-displacement step," Soil Dynamics and Earthquake Engineering, vol. 43, pp. 380-397, 2012.

[12] F. Mazza and A. Vulcano, "Effects of near-fault ground motions on the nonlinear dynamic response of base-isolated r.c. framed buildings," Earthquake Engineering \& Structural Dynamics, vol. 41, no. 2, pp. 211-232, 2012.

[13] C. Liu, P. Sun, and R. Shi, "Seismic response analysis and control of frame structures with soft first storey under nearfault ground motions," Advances in Civil Engineering, vol. 2020, Article ID 2642431, 13 pages, 2020.

[14] W. Pu, M. Wu, B. Huang, and H. Zhang, "Quantification of response spectra of pulse-like near-fault ground motions," Soil Dynamics and Earthquake Engineering, vol. 104, pp. 117-130, 2018.

[15] J. I. Baez and E. Miranda, "Amplification factors to estimate inelastic displacement demands for the design of structures in the near field," in Proceedings of the 12th World Conference On Earthquake Engineering, Auckland, New Zealand, January 2000.

[16] A. K. Chopra and C. Chintanapakdee, "Inelastic deformation ratios for design and evaluation of structures: single-degreeof-freedom bilinear systems," Journal of Structural Engineering, vol. 130, no. 9, pp. 1309-1319, 2004.

[17] S. Yaghmaei-Sabegh, "Application of wavelet transforms on characterization of inelastic displacement ratio spectra for pulse-like ground motions," Journal of Earthquake Engineering, vol. 16, no. 4, pp. 561-578, 2012.

[18] J. Ruiz-García, "Inelastic displacement ratios for seismic assessment of structures subjected to forward-directivity nearfault ground motions," Journal of Earthquake Engineering, vol. 15, no. 3, pp. 449-468, 2011.

[19] Z. Chang, F. De Luca, and K. Goda, "Near-fault acceleration pulses and non-acceleration pulses: effects on the inelastic displacement ratio," Earthquake Engineering \& Structural Dynamics, vol. 48, no. 11, pp. 1256-1276, 2019.

[20] N. Rahgozar, A. S. Moghadam, and A. Aziminejad, "Inelastic displacement ratios of fully self-centering controlled rocking systems subjected to near-source pulse-like ground motions," Engineering Structures, vol. 108, pp. 113-133, 2016.

[21] W.-P. Wen, C.-H. Zhai, S. Li, Z. Chang, and L.-L. Xie, "Constant damage inelastic displacement ratios for the nearfault pulse-like ground motions," Engineering Structures, vol. 59, pp. 599-607, 2014.

[22] J. Ruiz-García and E. Miranda, "Inelastic displacement ratios for design of structures on soft soils sites," Journal of Structural Engineering, vol. 130, no. 12, pp. 2051-2061, 2004.

[23] J. Ruiz-García and E. Miranda, "Inelastic displacement ratios for evaluation of structures built on soft soil sites," Earthq Eng Struct Dyn, vol. 35, no. 6, pp. 679-694, 2006.

[24] F. Khoshnoudian and E. Ahmadi, "Effects of inertial soilstructure interaction on inelastic displacement ratios of SDOF oscillators subjected to pulse-like ground motions," Bulletin of Earthquake Engineering, vol. 13, no. 6, pp. 1809-1833, 2015.

[25] S. Akkar, U. Yazgan, and P. Gulkan, "Deformation limits for simple non-degrading systems subjected to near-fault ground motions," in Proceedings of the 13th World Conference On Earthquake Engineering, British Columbia, Vancouver, Canada, August 2004.

[26] C. Zhai, S. Li, L. Xie, and Y. Sun, "Study on inelastic displacement ratio spectra for near-fault pulse-type ground motions," Earthquake Engineering and Engineering Vibration, vol. 6, no. 4, pp. 351-355, 2007.

[27] J. W. Baker, "Quantitative classification of near-fault ground motions using wavelet analysis," Bulletin of the Seismological Society of America, vol. 97, no. 5, pp. 1486-1501, 2007.

[28] C. Zhai, Z. Chang, S. Li, Z. Chen, and L. Xie, "Quantitative identification of near-fault pulse-like ground motions based on energy," Bulletin of the Seismological Society of America, vol. 103, no. 5, pp. 2591-2603, 2013.

[29] S. K. Shahi and J. W. Baker, "An efficient algorithm to identify strong-velocity pulses in multicomponent ground motions," Bulletin of the Seismological Society of America, vol. 104, no. 5, pp. 2456-2466, 2014.

[30] Z. Chang, X. Sun, C. Zhai, J. X. Zhao, and L. Xie, “An improved energy-based approach for selecting pulse-like ground motions," Earthquake Engineering \& Structural Dynamics, vol. 45, no. 14, pp. 2405-2411, 2016.

[31] G. Zhao, L. Xu, and L. Xie, "A simple and quantitative algorithm for identifying pulse-like ground motions based on zero velocity point method," Bulletin of the Seismological Society of America, vol. 106, no. 3, pp. 1011-1023, 2016.

[32] C. Zhai, C. Li, S. Kunnath, and W. Wen, "An efficient algorithm for identifying pulse-like ground motions based on significant velocity half-cycles," Earthquake Engineering \& Structural Dynamics, vol. 47, no. 3, pp. 757-771, 2018.

[33] J. D. Bray and A. Rodriguez-Marek, "Characterization of forward-directivity ground motions in the near-fault region," Soil Dynamics and Earthquake Engineering, vol. 24, no. 11, pp. 815-828, 2004. 
[34] E. Miranda, "Inelastic displacement ratios for structures on firm sites," Journal of Structural Engineering, vol. 126, no. 10, pp. 1150-1159, 2000.

[35] I. Iervolino, E. Chioccarelli, and G. Baltzopoulos, "Inelastic displacement ratio of near-source pulse-like ground motions," Earthq Eng Struct Dyn, vol. 41, no. 15, pp. 2351-2357, 2012.

[36] G. P. Mavroeidis, G. Dong, and A. S. Papageorgiou, "A mathematical representation of near-fault ground motions," Bulletin of the Seismological Society of America, vol. 93, no. 3, pp. 1099-1131, 2003.

[37] American Society of Civil Engineering (Asce), Seismic Evaluation and Retrofit of Existing Buildings, ASCE/SEI, Reston, VI, US, 2017.

[38] G. Baltzopoulos, E. Chioccarelli, and I. Iervolino, "The displacement coefficient method in near-source conditions," Earthquake Engineering \& Structural Dynamics, vol. 44, no. 7, pp. 1015-1033, 2015.

[39] S. Yaghmaei-Sabegh, S. Neekmanesh, and J. Ruiz-García, "Evaluation of the coefficient method for estimation of maximum roof displacement demand of existing buildings subjected to near-fault ground motions," Soil Dynamics and Earthquake Engineering, vol. 121, pp. 276-280, 2019.

[40] G. De Francesco, "Constant-ductility inelastic displacement ratios for displacement-based seismic design of self-centering structures," Earthquake Engineering \& Structural Dynamics, vol. 48, no. 2, pp. 188-209, 2019. 